Provided for non-commercial research and education use. Not for reproduction, distribution or commercial use.

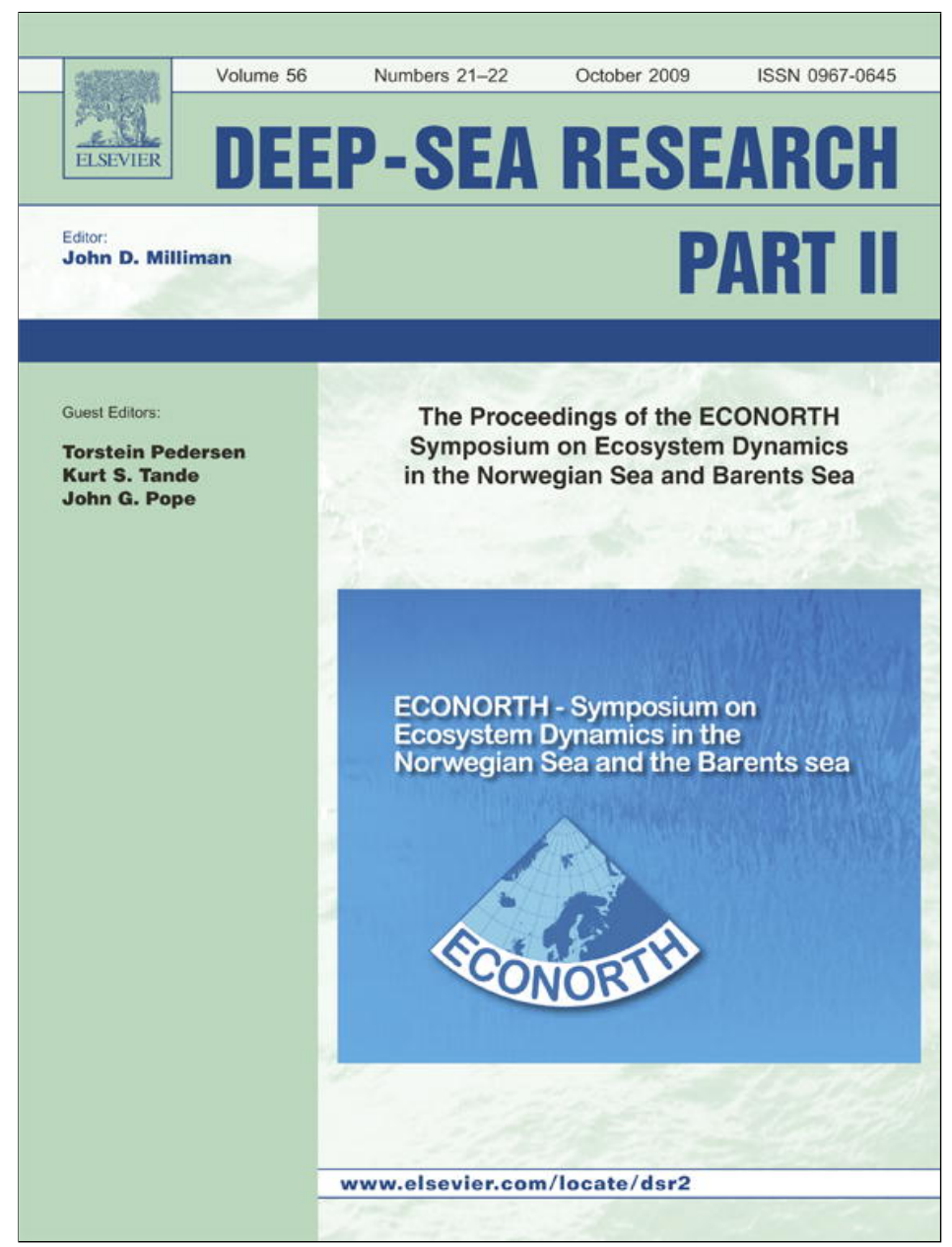

This article appeared in a journal published by Elsevier. The attached copy is furnished to the author for internal non-commercial research and education use, including for instruction at the authors institution and sharing with colleagues.

Other uses, including reproduction and distribution, or selling or licensing copies, or posting to personal, institutional or third party websites are prohibited.

In most cases authors are permitted to post their version of the article (e.g. in Word or Tex form) to their personal website or institutional repository. Authors requiring further information regarding Elsevier's archiving and manuscript policies are encouraged to visit:

http://www.elsevier.com/copyright 


\title{
Biological processes and links to the physics
}

\author{
Hans-Harald Hinrichsen * \\ Leibniz Institute of Marine Sciences, Düsternbrooker Weg 20, D 24105 Kiel, Germany
}

\section{A R T I C L E I N F O}

\section{Article history:}

Accepted 11 November 2008

Available online 3 December 2008

Keywords:

Environmental variability

Migration

Transport

Coupled processes

Individual-based models

Predictability

\begin{abstract}
A B S T R A C T
Analysis of the temporal and spatial variability of biological processes and identification of the main variables that drive the dynamic regime of marine ecosystems is complex. Correlation between physical variables and long-term changes in ecosystems has routinely been identified, but the specific mechanisms involved remain often unclear. Reasons for this could be various: the ecosystem can be very sensitive to the seasonal timing of the anomalous physical forcing; the ecosystem can be contemporaneously influenced by many physical variables and the ecosystem can generate intrinsic variability on climate time scales. Marine ecosystems are influenced by a variety of physical factors, e.g., light, temperature, transport, turbulence. Temperature has a fundamental forcing function in biology, with direct influences on rate processes of organisms and on the distribution of mobile species that have preferred temperature ranges. Light and transport also affect the physiology and distribution of marine organisms. Small-scale turbulence determines encounter between larval fish and their prey and additionally influences the probability of successful pursuit and ingestion.

The impact of physical forcing variations on biological processes is studied through long-term observations, process studies, laboratory experiments, retrospective analysis of existing data sets and modelling. This manuscript reviews the diversity of physical influences on biological processes, marine organisms and ecosystems and their variety of responses to physical forcing with special emphasis on the dynamics of zooplankton and fish stocks.
\end{abstract}

(c) 2008 Elsevier Ltd. All rights reserved.

\section{Introduction}

Marine ecosystem processes are controlled to a large extent by physical forcing. The most important physical oceanographic variables that influence biology are thought to be sea-surface temperature (SSTs), mixed-layer depth, thermocline depth, upwelling strength, upper-ocean current fields and sea ice. The interaction between physical and biological processes occurs at a wide range of temporal and spatial scales, from $\mu \mathrm{m}$ and $\mathrm{ms}$, to hundreds of kilometers, and months or years (Levin, 1992). The physical forcing is, for example, obvious on time scales where variations in sea-surface temperature and upwelling strongly control productivity and growth (e.g., Painting et al., 1998; Borja et al., 1998). Variability of physical processes at larger temporal and spatial scales includes active movements of larger individuals (migration) as well as passive transport of small individuals (advection). Variation can occur at hydrographic discontinuities and transition zones (fronts, clines, gyres) at daily to monthly periods (Munk, 1993), as well as at large-scale oceanic circulations

\footnotetext{
* Fax: +494316004566 .

E-mail address: hhinrichsen@ifm-geomar.de
}

patterns, induced by atmospheric forcing variability and climate changes occurring at multi-year frequency (Alheit et al., 2005). But on longer time scales, there is still a high degree of uncertainty concerning the mechanisms that are involved when changes in physical oceanographic conditions influence ocean biology.

Data analyses and modeling have led to recent advances in understanding the influences of physical processes on biology and to the recognition of inherent variability of marine biological communities on various spatial and temporal scales (deYoung et al., 2004). The understanding of the linkage between physics and biology of marine ecosystems has come about as a result of various methodologies, from laboratory experiments and field measurements to modeling and data synthesis, and the interaction among them. The objective of most applications coupling physics and biology is to understand and predict spatial and temporal changes in production, distribution and structure of populations in an ecosystem.

The present contribution aims to disentangle interactions between physics and (1) the reproductive biology of zooplankton and fishes with special emphasis on climatic, atmospheric and hydrographic forcing conditions, and (2) species interactions affecting zooplankton and early and juvenile fish life stage development and survival. 
2. From field data, laboratory experiments to modeling studies: analysis of biophysical processes

It is very common to use simplified atmospheric condition indices in order to describe how variability of biological conditions could be influenced by physical factors. Fromentin and Planque (1996) and Beaugrand et al. (2002) demonstrated that, for example, Calanus finmarchicus abundance is inversely and highly significantly correlated with the North Atlantic Oscillation (NAO). The NAO has its greatest influence on water temperatures and hydrographic variability in the North Atlantic during winter time (Marshall et al., 2001; Ottersen et al., 2001). Usually, the NAO data used are based on normalized differences in atmospheric pressure between Lisbon, Portugal and Iceland (Fig. 1A). A large fraction of C. finmarchicus overwinters at depth in the northeast Atlantic and is transported into the North Sea each year. From 1988 to 1995, the period of highest NAO-index values ever recorded, the abundance of this copepod species was relatively low (Fig. 1B). It was hypothesized that unfavourable growth conditions led to

(A)

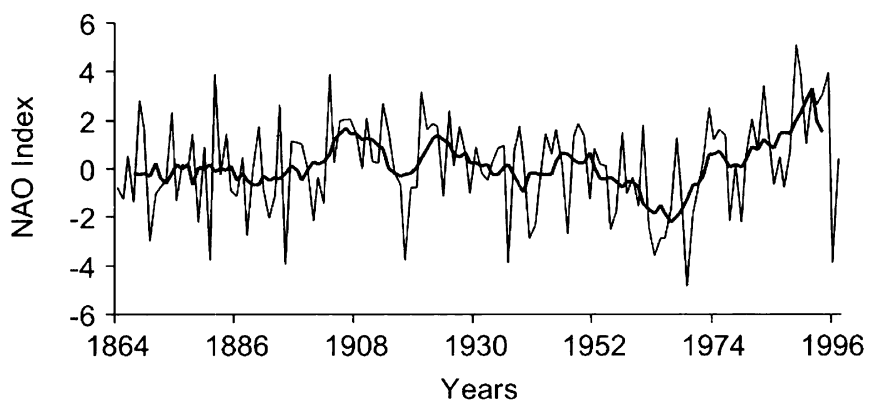

(B)

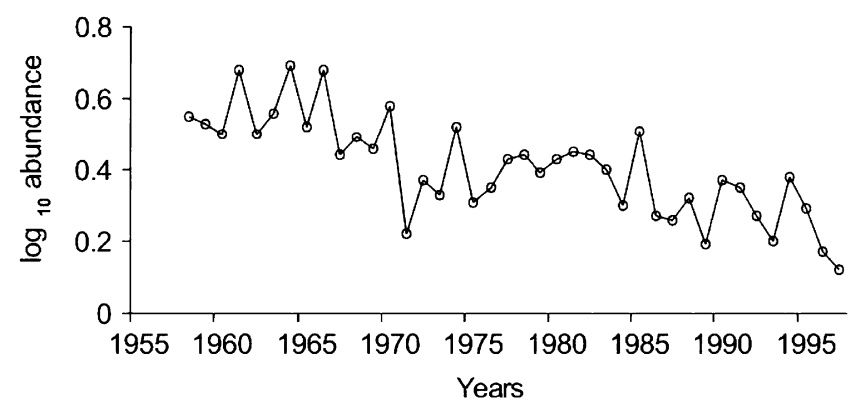

(C)

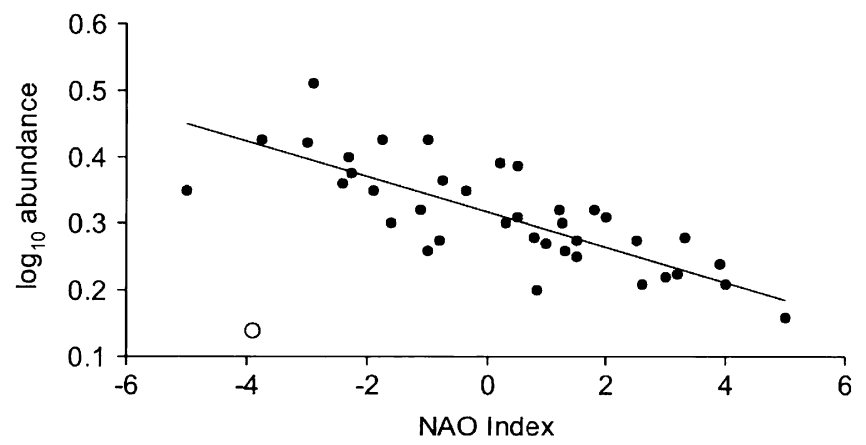

Fig. 1. (A) North Atlantic Oscillation (NAO) December-March index based on the averaged pressure difference between the Acores and Iceland from 1864 to 1997, the bold line is a 3 -year moving average, (B) $\log _{10}$ abundance of Calanus finmarchicus averaged for the North Sea in the months January-June for the years 1958-1997 and (C) linear regression between the $\log _{10}$ abundance of Calanus finmarchicus in the northeast Atlantic and the NAO-index from 1958 to 1996; the open circle is for 1996 (Reid et al., 1998b). the decay of $C$. finmarchicus in the northeast Atlantic, which also may have contributed to reduced populations in the North Sea. Two independent modelling studies have shown changes in the volume of winter water advected into the North Sea during winter after 1987 (Reid et al., 1998a; Stephens et al., 1998). As part of a hydrodynamic response to the observed atmospheric changes since the late 1980s, there is evidence for a possible acceleration in the advection of warmer water from off the coast of Iberia northward into the shelf-edge current to the west of the UK and into the northern North Sea. Planque and Taylor (1998) also suggested that the mechanisms contributing to the changing levels of abundance of $C$. finmarchicus may operate through changes in sea-surface temperature. Planque and Reid (1998) have established a relationship between the abundance of this species and the NAO-index to estimate future levels of abundance (Fig. 1C).

Implications exist that recruitment variability of fish species is based principally on physical factors or processes. In the Bay of Biscay, the hypothesis that physical factors have an influence on fish recruitment has been confirmed, e.g., for anchovy (Borja et al., 1998). Oceanographic conditions in the Bay of Biscay in spring and summer, influenced by north-easterly winds of medium and low intensity, promote high recruitment levels of anchovy. Different factors affecting productivity were linked to north-easterly winds, namely weak upwelling and an extension of the area of the Bay influenced by river runoff. Variations in upwelling and in the extension of the area influenced by river runoff along the shelf explained about $60 \%$ of the variability in the recruitment of the Bay of Biscay anchovy for the time period 1967-1996 (Fig. 2). Borja et al. (1998) also analysed the importance of other physical factors such as wind-induced turbulence and the stability of the water column for anchovy recruitment. The level of upwelling and the degree of turbulence explained $67 \%$ of the recruitment variability if a time period from 1967 to 1989 was considered. Thus it could be deduced that turbulence had only a negligible role in the determination of recruitment compared with upwelling. Taking the whole time series into consideration, the turbulence would negatively affect the index of recruitment and together with upwelling explained $57 \%$ of the variability.

Temperature-dependent processes are numerous across species and marine ecosystems (e.g., Campana, 1996; Fowler and Jennings, 2003; Zeldis et al., 2005), but result from a multitude of interrelated mechanisms. Weak year classes of fish species could often be directly associated with severe winters or due to low water temperatures during spawning, which have the potential to strongly influence the production of fish species. Temperature influences metabolic processes and, other than prey availability, is the single most important factor that determines growth rates in fish (Brett, 1979). Houde (1989) investigated the effect of temperature and implied latitudinal effects on vital rates of marine fish larvae. He postulated that the large increase in growth rates, observed at higher temperatures must be supported by increased food consumption. He also hypothesized that firstfeeding larvae were more likely to starve in warm environments, as a result of their relatively larger ingestion requirements, increased metabolism, and low assimilation efficiency. In many cases, the temperature effect of enhanced larval fish survival through higher growth rates is probably augmented by temperature-dependent zooplankton dynamics (Limburg, 1996). For Acartia spp. and Pseudocalanus elongatus, Klein-Breteler and Schogt (1994) and Klein-Breteler et al. (1995) used the Bělehrádek function to estimate the development time from eggs to adults, showing that the higher the temperature, the faster the stage development. Secondly, they showed a physiological temperature optimum with higher mortality rates when the temperature departs dramatically either side of this optimum. 


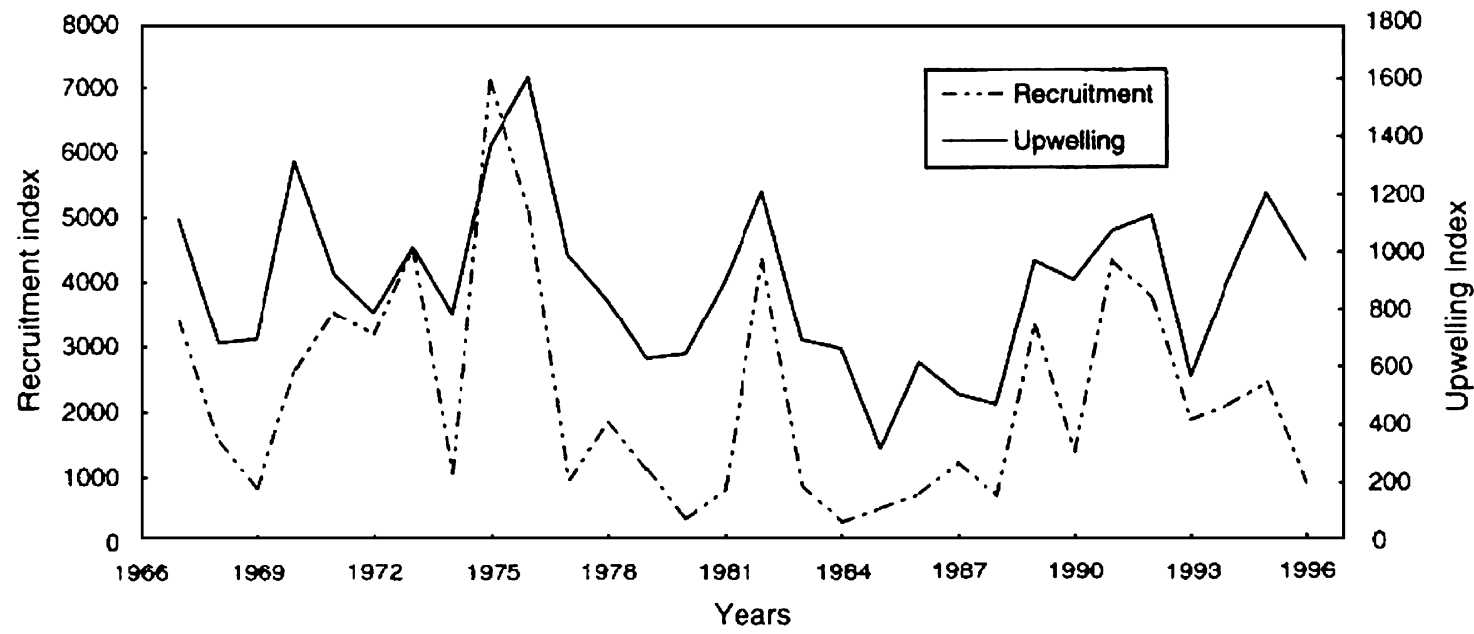

Fig. 2. Recruitment (thousand individuals caught by cohort and boat by year and upwelling, $\mathrm{m}^{3} \mathrm{~s}^{-1} \mathrm{~km}^{-1}$ from March-July) plotted for the years $1967-1996$ (Borja et al. 1998).

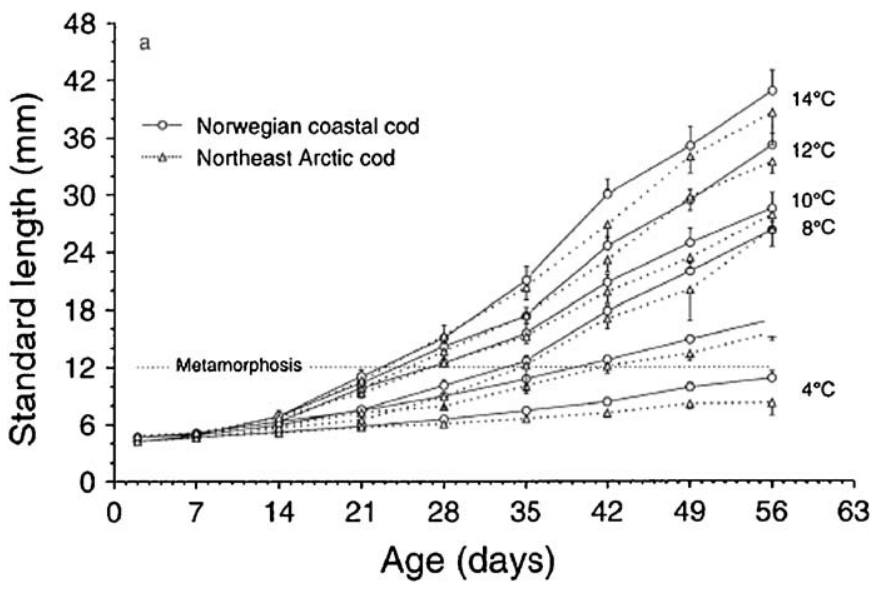

Fig. 3. Standard length of Norwegian coastal cod and northeast Arctic cod reared at different temperatures. Vertical lines indicate 2 SE of the mean (Otterlei et al., 1999).

Otterlei et al. (1999) conducted rearing experiments with Norwegian coastal and northeast Arctic Atlantic cod to investigate temperature and size-specific growth under food saturation. Somatic growth in length and weight (not shown) for both stocks increased successively with increasing temperature (Fig. 3), and larval stage duration decreased rapidly as temperature increased. Larval and juvenile weight-specific growth rates were temperature and size dependent (Fig. 4), exhibiting a dome-shaped relationship between weight-specific growth rate and body size. Growth rate reached a peak level at a specific larval size and decreased rapidly during the juvenile stage.

Laboratory experiments, as the one described above, enable the investigation of processes difficult to observe in the field. Output of this experimental approach, wherein experimental controls are imposed that allow conditions of interest to be systematically varied while holding other factors constant, are essentially to individual-based models. Recent individual-based models for larval fish have added more biological realism by including functions describing the effects of physical factors on biological processes. Thus, current parametrizations, as obtained from rearing experiments, enable a more dynamic response to changes in the physical environment.

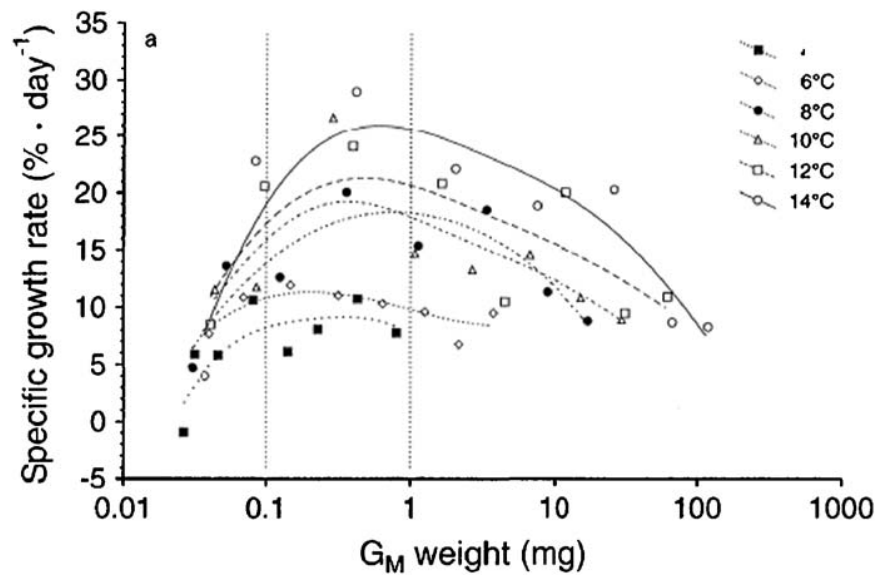

Fig. 4. Weight-specific growth rate versus geometric mean dry weight of Norwegion coastal cod reared under different regimes. The fitted lines (least squares) indicate the general trends in growth. Data from replicates are combined (Otterlei et al., 1999).

Theoretical work suggests that small-scale turbulence enhances encounter rates between larval fish and their prey (Rothschild and Osborn, 1988) and additionally influences the probability of successful pursuit and ingestion of prey (Dower et al., 1997). However, analysis of the influence of small-scale turbulence on larval fish feeding overall indicated that turbulence can have both beneficial or detrimental effects on larval fish ingestion depending on magnitude of the turbulence and on larval behaviour (MacKenzie et al., 1994). A dome-shaped relationship was found where ingestion rates are maximal at intermediate rather than high levels of turbulence (Fig. 5). The reduction in pursuit success in highly turbulent environments negates the increase in encounter rate.

Recent studies have identified the larval and early juvenile life stages of Baltic sprat to be critical for the survival rate of a yearclass (Baumann et al., 2006). Prey abundance was found to be linked to larval survival success (Voss et al., 2006), but an analysis identifying the functional relationship and relative importance of other environmental factors is still missing. Therefore sprat larval feeding was investigated in 2002 during three cruises, covering the main spawning time of sprat in the Bornholm Basin, Baltic Sea. A study performed by Voss et al. (2008) demonstrated that the 


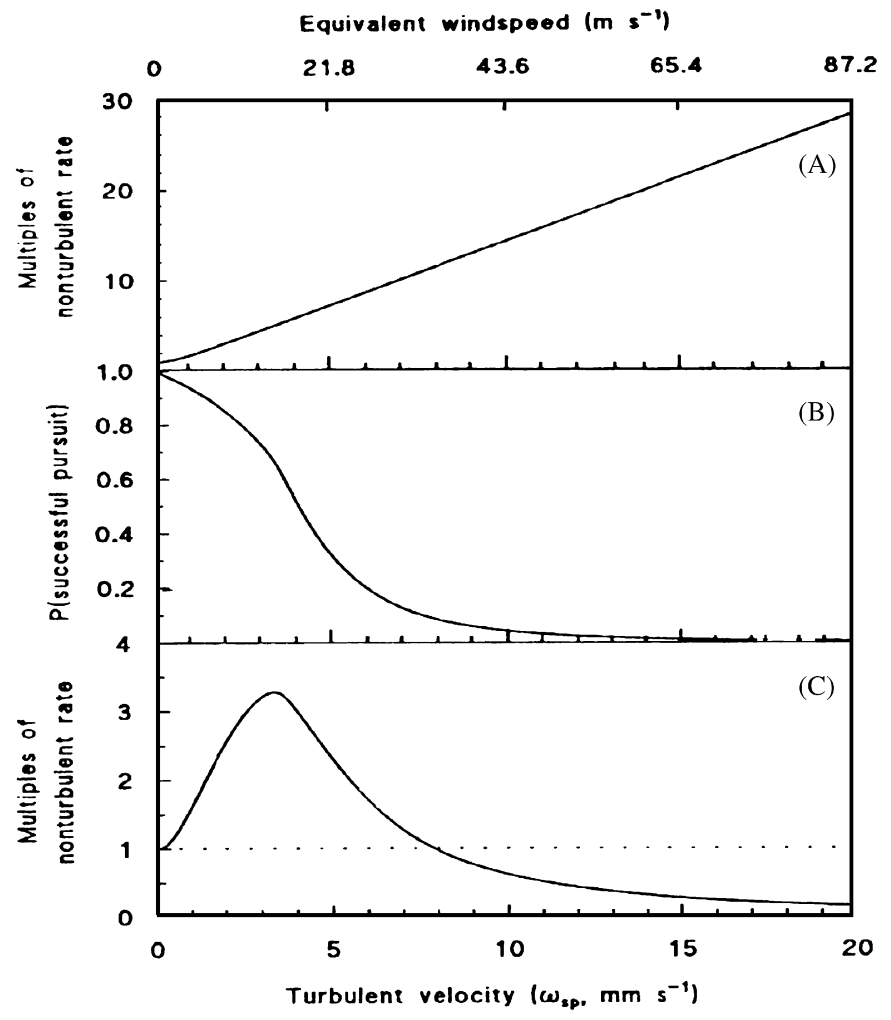

Fig. 5. The influence of turbulence on (A) relative encounter, (B) the probability of successful pursuit and $(C)$ relative ingestion in larval cod subject to turbulence (MacKenzie et al., 1994).

feeding success (number of prey items in the gut) of Baltic sprat larvae is determined not only by the density of potential prey organisms, but rather by a number of simultaneously acting key environmental factors. An extension of generalised additive models (GAMs) was adopted that allows the inclusion of interaction terms in a non-parametric regression model. The model of sprat larval feeding success explained approximately $80 \%$ of the variance in the data and was based on the following environmental factors: cubed wind speed as proxy for small-scale turbulence rates, degree of cloudiness as proxy for light conditions (Fig. 6) and prey density in combination with a feeding period-cloudiness interaction term. After inclusion of the interaction term and exclusion of temperature as a single factor, most of the variables retained their general effects on the larval feeding success. In summary, the additive model suggests that the best feeding conditions for sprat larvae occurred on warm, sunny, moderately windy days in high prey density regions at the edge of the deep basin $(\sim 70-80 \mathrm{~m})$. It further can be deduced that Baltic sprat larvae need $\sim 9 \mathrm{~h}$ after sunrise to fill their guts.

Since ingestion rate is directly correlated to growth, the effect of cubed wind speed on gut content of Baltic sprat obtained from the GAM analysis was similar to the dome-shaped relationship between larval ingestion rate and turbulence (Fig. 5) delineated by MacKenzie et al. (1994) and simulated for larval cod and herring by Fiksen et al. (1998). According to the additive model, best feeding conditions for sprat larvae occur when wind conditions are at intermediate levels $\left(\sim 7-9 \mathrm{~m} \mathrm{~s}^{-1}\right)$.

Results of meta-analyses of oceanographic, nutrient, phytoand zooplankton as well as fisheries data and climate indices for the Central Baltic Sea were used in a principal component analysis and chronological clustering (Möllmann et al., 2006). Three different ecosystem states in the Central Baltic Sea ecosystem were identified. This integrated analysis using multivariate statistics demonstrated different regimes with major changes in the Baltic Sea ecosystem at the end of the 1980s, consistent with other areas of the world ocean, and during the early 1990s. The different regimes in the ecosystem are clearly visible relating the first two principal components to each other (Fig. 7). The shift between regimes 1 and 2 (1987-1989) is identifiable by the rapid changes of the PC1-scores, while the shift between regimes 2 and 3 (1990-1994) can be seen by the rapid change of the PC2-scores. Principally, PC1 indicated the increasing trend of increasing temperature and decreasing salinity since the late 1980s in parallel to the unusual positive state of the North Atlantic Oscillation (Fonselius and Valderrama, 2003; Hänninen et al., 2000). PC2 summarizes mainly trends in the dynamics of the deep water in the deep water of the Baltic Basins, i.e., salinity and nutrient conditions. The composite temporal trends of temperature and salinity caused alterations on all trophic levels of the Central Baltic Sea ecosystem, thus the shifts in the food web of the ecosystem can be interpreted as initiated by climate-driven changes in the abiotic environment, and further modified by fishing and internal ecosystem processes. This finally led to a change of the ecosystem from cod- to sprat-dominated (Köster et al., 2005).

Most of the analyses of biophysical processes undertaken previously have been focused on particular geographic areas or upon limited questions that address a small number of physical processes affecting biology. But previous studies have generated extensive data series that would be extremely valuable to understanding ecosystem processes and their changes. Hence, more effort should be put on the development of new, multivariate, and more powerful statistical methodologies to quantitatively assess them. Coordinated approaches are required to enable systematic investigation of the impact of particular physical processes on biology designed to identify all of the key variables involved and to establish the relationships among them. Furthermore, these approaches must have the ability to identify apparent synchronies and asynchronies between these processes. These new methodologies should not necessarily have the only goal to resolve, e.g., species-specific complex ecosystem processes, but should demonstrate their usefullness in developing a framework for an integrated ecosystem assessment. In view of the uncertainty in our knowledge about physical processes, it is not surprising that knowledge about the impact of these processes on biology is far from being complete and also uncertain. Thus methods to be used for future analyses have to take into account uncertainties associated with both limitations to process understanding and ecological complexity. Besides the development of new methodologies, more observational data and techniques are required to parameterize processes of prey-predator interactions at scales that are relevant for larval fish such as predator escape, prey encounter, capture and feeding success (e.g., Browman, 1996; Mariani et al., 2007).

\section{Transport}

The maintenance of distinct zooplankton and fish populations requires that their juvenile stages recruit to their source population and that mixing between populations is restricted. However, many marine species are sedentary as reproductive adults but are redistributed as juveniles by currents during their pelagic phase. Many fish species, for instance, use different locations for spawning, larval development, larval and juvenile feeding, and adult feeding. Their life histories require connections between these spatially disaggregated locations to close the life cycle. Learned behaviour might play an important role in maintaining 
(A)

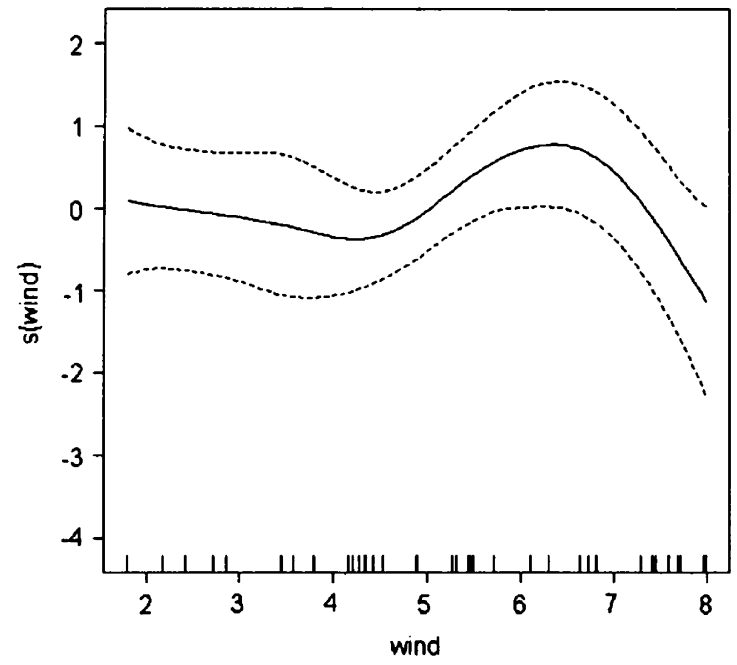

(C)

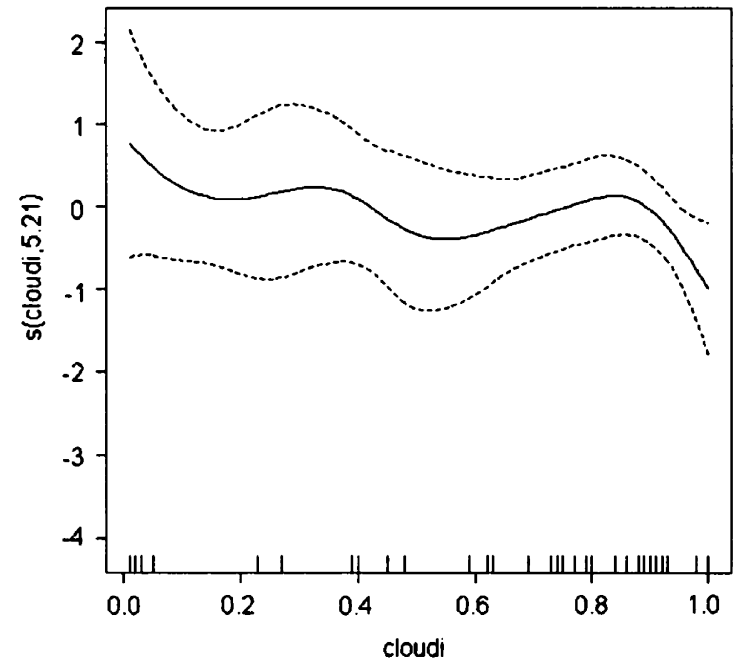

(B)

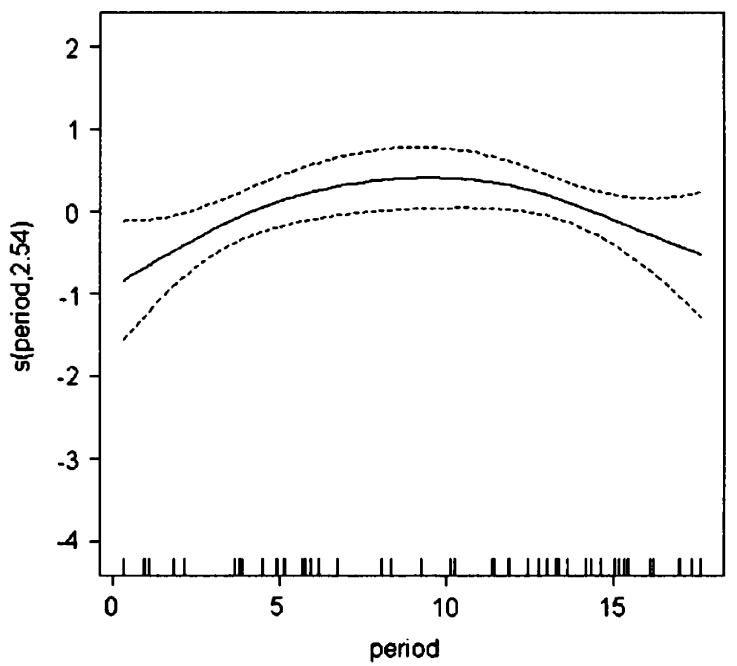

(D)

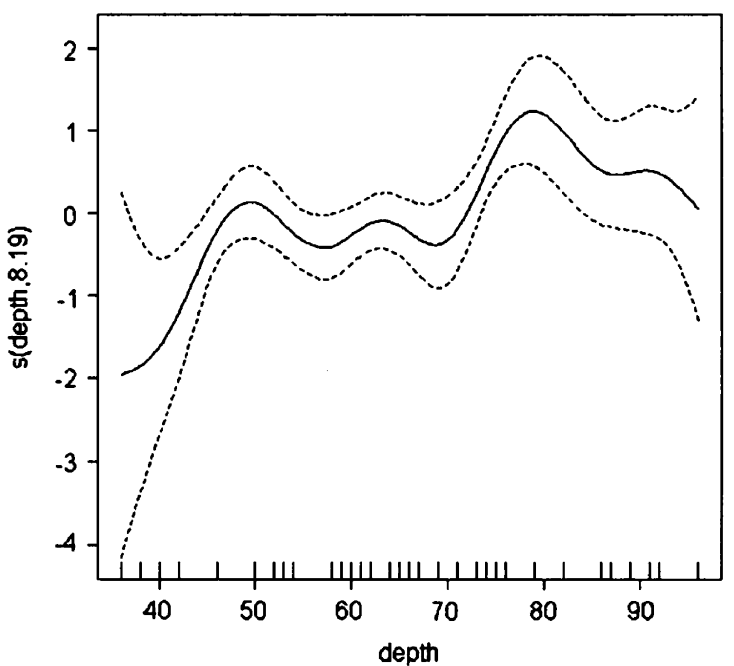

Fig. 6. General additive model (GAM) output for Baltic sprat larval feeding. Values $<0$ indicate a negative effect of (A) wind-induced turbulence, (B) feeding period, (C) cloudiness and (D) bottom depth on numbers of prey in the gut and values $>0$ that the variable has a positive effect (Voss et al., 2008).

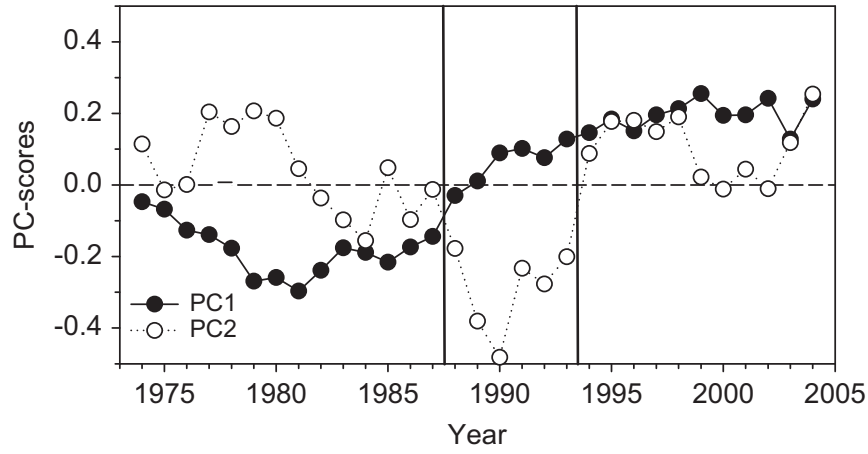

Fig. 7. Time series of the scores of the first two principal components PC1 and PC2 for the analysis for the Central Baltic Sea; vertical lines indicate Regime Shifts detected by chronological clustering (Möllmann et al., 2006).

patterns of connectivity or isolation (e.g., Hay et al., 2001), which is most likely influenced by variable hydrographic and atmospheric forcing conditions, leading to spatio-temporal differences in larval transport. This additionally may affect recruitment success of fish stocks, because retention or dispersion of larvae from the spawning grounds to areas suitable or unsuitable for larval survival has been identified as one of the key processes influencing recruitment success in fish stocks (e.g., Werner et al., 1996; Heath and Gallego, 1998; Hinrichsen et al., 2002). Advective transports can be accompanied by propagation of individuals or cohorts of different origin as well as local populations of single stocks, thus, within the same area leading to mixing of juveniles.

Advective propagation of Baltic sprat early life stages spawned on different spawning grounds was analysed by detailed drift model simulations for 1979-present (Hinrichsen et al., 2006). The results generated characteristic patterns of horizontal 0 group distributions in the Baltic, which were in good accordance with field measurements of hydroacoustically detected juvenile sprat. The modeling approach enabled the identification of potential nursery grounds for sprat originating from different spawning grounds. Mainly, westerly winds prevail over the Baltic Sea. This leads to, on average, higher abundance of juvenile sprat along the southern and eastern coasts of the Baltic. Information on the distribution of juveniles derived from hydroacoustic surveys in 12 out of 24 years enabled the direct comparison with simulated distributions. Both the simulated and the observed 
juvenile distributions show the same tendencies in transport with respect to physical forcing conditions.

Detailed transport analyses of larval and juvenile Baltic sprat based on simulated drifter positions were performed by Baumann et al. (2006). The initial drifter positions at release were based on average sprat egg distributions, assumed as a proxy for the spatial distribution of first-feeding sprat larvae. The vast majority of particles were released inside the 40-m isobath of the four major spawning grounds: Arkona Basin, Bornholm Basin, Gdansk Deep and Gotland Basin. For an integrated view of annual drift patterns, daily bottom depths were averaged for nine drifter cohorts per year across all particles, regardless of their individual position in space. For all drifter cohorts per year, the final particle positions at specific dates were indicative of considerable differences in Baltic circulation patterns. Two main features could be distinguished: (i) years of predominant particle retention within the central deep basins (e.g., 1997; Fig. 8A), and (ii) years of large-scale particle displacement and dense accumulation along southern, south-

(A)

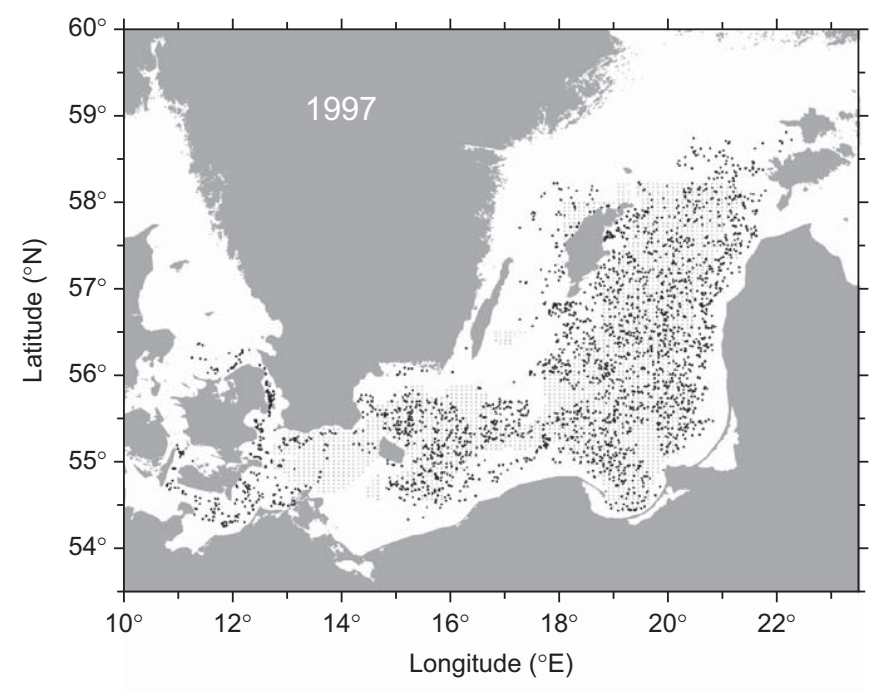

(B)

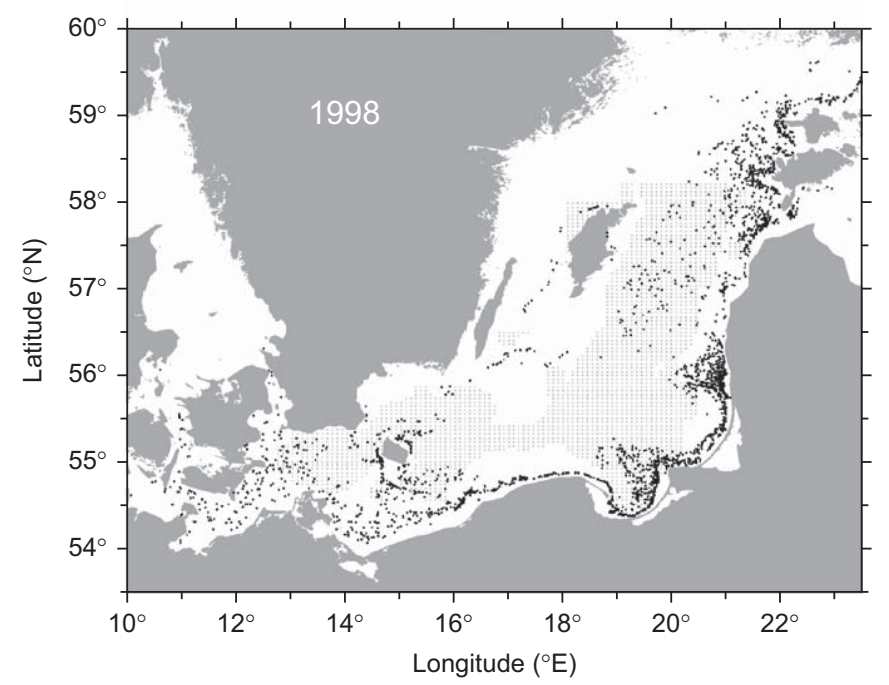

Fig. 8. Distribution of Lagrangian particle (black dots) released on 10 July within areas of Baltic sprat (Sprattus sprattus) spawning effort and tracked for 50 days in (A) 1997 and (B) 1998. The bathymetry of the study area is shown in panel (A); the particle seeding pattern (grey dots) is depicted in panel (B). Water abbreviations: AB, Arkona Basin; BB, Bornholm Basin; GB, Gotland Basin; GD, Gdansk Deep. Land abbreviations: DK, Denmark; Ger, Germany; Lat, Latvia; Li, Lithuania (Baumann et al., 2006). eastern and eastern Baltic coastlines (e.g., 1998; Fig. 8B). Particle drift towards Swedish coastlines, caused by strong easterly winds, was generally negligible. The results suggested that during years with a large number of low-pressure systems passing over the Baltic, a high fraction of larvae may be transported to southern and eastern coastal environments of the central Baltic Sea. Conversely, high-pressure systems over Scandinavia and the eastern Baltic Sea during the spawning season are characterized by weak easterly or northerly winds and correspondingly the juveniles were largely retained within the deep water region of the spawning areas.

However, when moving from particles to living organisms, inferences drawn from drift simulations are based on the assumption that passive drifter trajectories reflect the average transport patterns of the planktonic species or life stages. In demersal fish like cod or flatfish, juvenile settlement concludes the susceptibility to ocean circulation and thus sets a natural limit to drift durations. Furthermore, the onset of active swimming behaviour or schooling may not necessarily preclude Lagrangian drift simulations if late larval or early juvenile stages start moving randomly within a water body that is subject to physical forcing (e.g., Allain et al., 2003). Generally, combined field and modeling exercises have clearly demonstrated that traditional sampling methodology is unable to identify variations in biological processes without considering flow dynamics and the impact of physical forcing conditions.

Physical properties simulated by the hydrodynamic model often agree well with known circulation features and observed physical conditions (e.g., Baltic Sea: Lehmann and Hinrichsen, 2000), i.e., a well-validated hydrodynamic model is a fundamental requirement to analyse transport as a process impacting on coupled biological processes. Future work is also required to investigate how the spatial resolution of hydrodynamic models can influence the predicted trajectories of particles and whether a model grid is fine enough to capture the appropriate horizontal mixing processes (Hinrichsen et al., 1997). Finally, there is a need for better parameterization of subgrid scale mixing processes in particle tracking models, i.e., processes that occur on smaller scales than the grid size of the hydrodynamic model (Gallego et al., 2007).

\section{Coupled biophysical models}

Modeling has become an essential component of integrated ocean research efforts. The coupling of circulation models with life history models of zooplankton and fish species can be utilized to examine rate-dependent processes (e.g., stage development, feeding, growth and survival) as well as estimating losses of individuals (e.g., Rose et al., 1993; Werner et al., 1996; Hinckley et al., 2001; Pedersen et al., 2001). These coupled models allow examination of rate-dependent processes of individuals in the context of their transport by utilizing biological relationships along their potential drift routes.

A combined biophysical modeling and field program on the population dynamics of $C$. finmarchicus is described by Pedersen et al. (2001). The modeling study preceded a large-scale sampling program covering the Norwegian shelf area and analysed how temperature variability affected the population dynamics of the copepod along the shelf during the reproductive period. Another objective of the modeling study was to identify the most likely source areas for $C$. finmarchicus at the northern Norwegian shelf during spring and summer.

In the study, Pedersen et al. (2001) had released copepod cohorts into simulated flow fields in order to detect the major tracking routes of the population. The whole population was 
divided into two components: an oceanic and a shelf component, which have different spawning and vertical migratory behaviours. The biological component of the coupled biophysical model described vertical migration, spawning behaviour and stage development of the copepod. The results indicated that C. finmarchicus was distributed along the major current branches in the Norwegian Sea, with fractions entering the Barents Sea, West Spitsbergen and the Norwegian Shelf (Fig. 9). One part of the population was found to remain for the whole generation time in the oceanic regime. The stage progression showed a difference regarding the initial origin of the cohort: copepods that developed in the deep-ocean area had a later spawning period compared to cohorts, which mainly reproduce in the near coastal regions (Fig. 10). The stage progression of the shelf component of the population had its peak between Julian days 50 and 70, while peak reproduction of the oceanic fraction of the population was delayed by about 50 days. Hence, the life history of this calanoid copepod deviated between one and three generations per year.

Variations in marine fish egg and larval transport have been suggested as one of the important factors affecting recruitment variability in fish stocks (Iles and Sinclair, 1982; Fortier and Leggett, 1985; Smith and Stoner, 1993; Lough et al. 1994). Recent modelling efforts to understand the causes of mortality of larval and juvenile fish have been focussed on examining the effects of advective and trophodynamic processes (e.g., Werner et al., 1996; Letcher et al., 1996; Hinrichsen et al., 2002). Motivation for this approach also stems from the observation that survival of larval fish could be dependent on circulation patterns for transport from the spawning ground to the nursery area; thus local biological and physical events may explain fish early life stage growth and survival patterns. Rates of growth and survival are often positively correlated during early life stages of marine fishes (Houde, 1987; Cowan and Shaw, 2002) and the former are most influenced by differences in temperature and food availability (Heath, 1992). Optimal habitats, therefore, are areas with high prey resources and adequate temperatures that support relatively high rates of growth. Coupled biophysical models considered the spatial heterogeneity in environmental conditions by integrating trophodynamics into three-dimensional hydrodynamic models. Several of these biophysical models have been established, e.g., for walleye pollock (Hermann et al., 1996, 2001; Hinckley et al., 1996), haddock off Scotland (Heath and Gallego, 1998, 2000), bay anchovy from Chesapeake Bay (Rose et al., 1999) and cod on

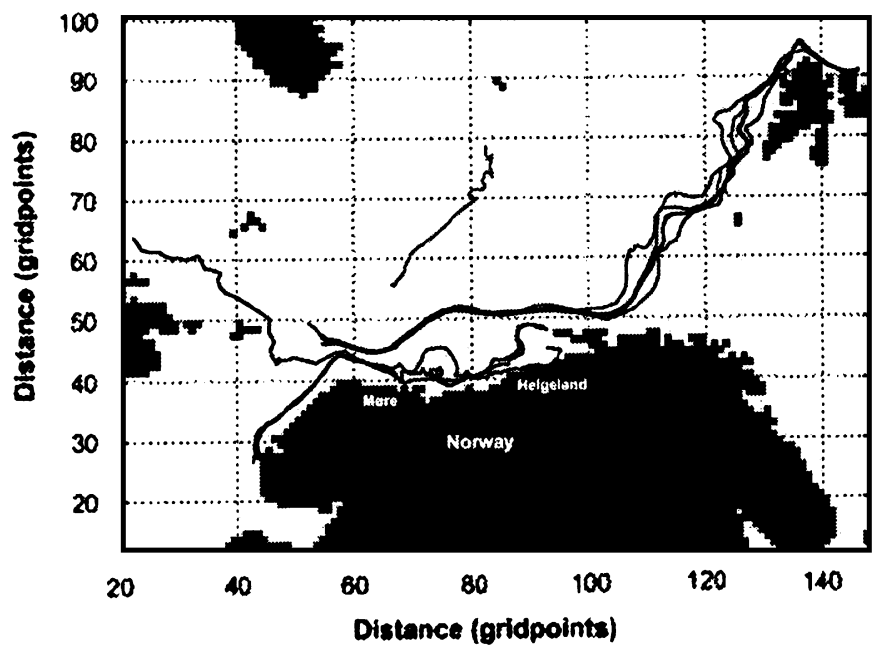

Fig. 9. Particle trajectories from the fraction of the population released in the oceanic, in the Faroe-Shetland region, on the shelf-break west of More and at the southern part of the Norwegian coast (Pedersen et al., 2001).

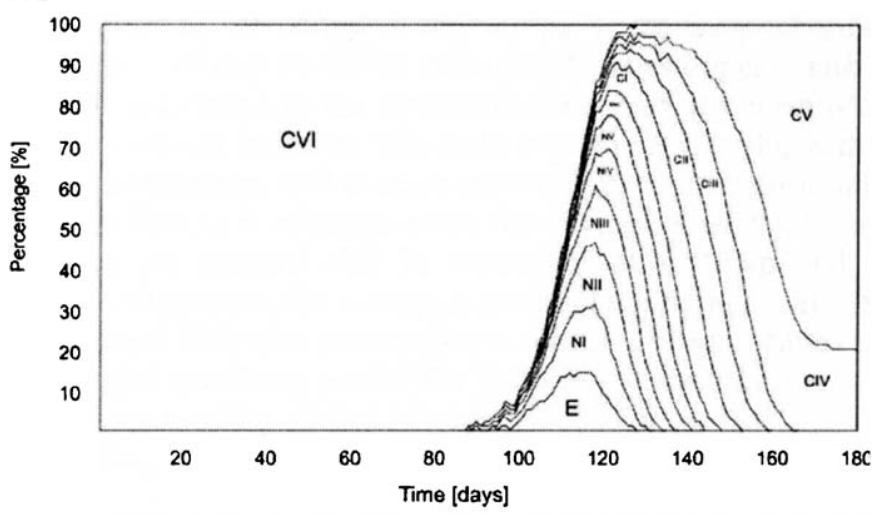

(B)

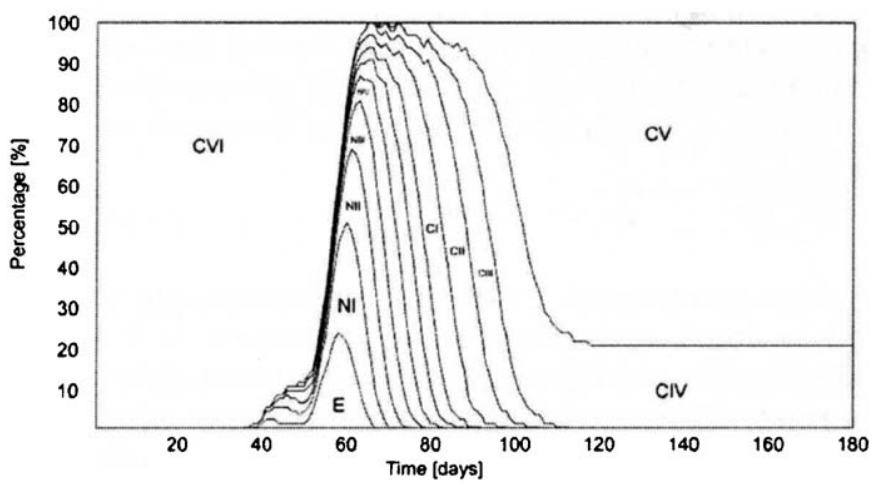

Fig. 10. Stage progression of C. Finmarchicus for (A) the fraction of the population originating from the oceanic regions, and (B) the population from the shelf regions (Pedersen et al., 2001).

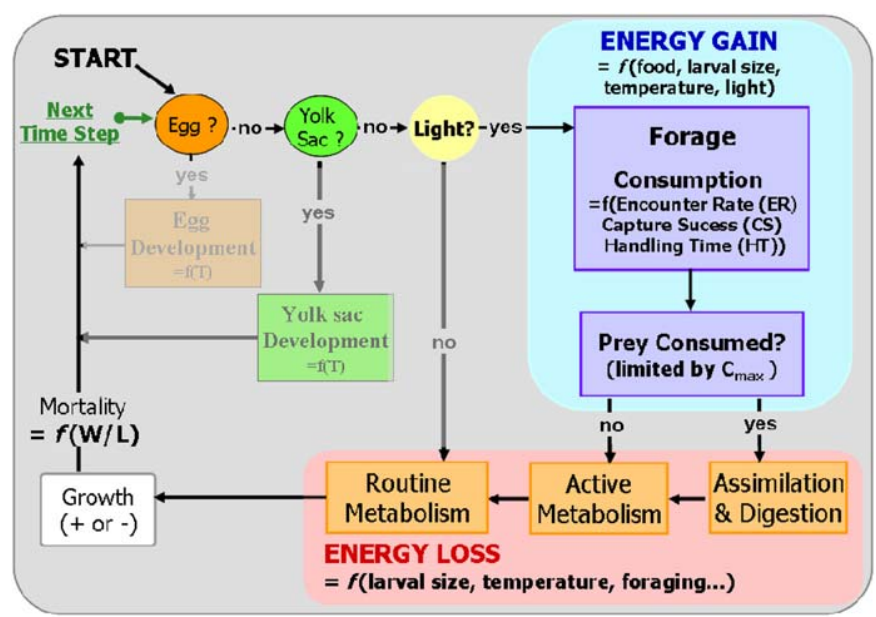

Fig. 11. Schematic of individual-based model on feeding, ingestion, growth and survival of larval fish.

Georges Bank (Werner et al., 1996, Lynch et al., 2001, Lough et al., 2005) and in the Baltic (Hinrichsen et al., 2002).

Subcomponents of those coupled biophysical models are in use for non-feeding stages, which simulate the development of eggs and yolk-sac larvae (Fig. 11). For these stages growth is exclusively based upon resorption of endogenous energy (yolk) reserves. The developmental rate during the embryonic period (egg stage) and the yolk-sac larval phase is primarily temperature dependent. Within the model, the encounter of prey, foraging, growth and survival of individual larvae is simulated by specific submodels in 
specific time steps. Along the transport routes within the coupled model, the larval environment consists of the prey fields, ambient temperature and turbulence determining both their growth and survival. To analyse growth and survival of larval fish, the following simulation output variables are obtained by using coupled biophysical models: (i) survival-dependent on minimum weight growth rates, (ii) days of starvation (when the amount of food ingested does not cover metabolic costs) and (iii) condition of larvae (weight) at specific length. Daily food consumption can be restricted to upper limits (maximum consumption of maximum weight at specific size) representing a satiation effect incorporated into the model to prevent over-feeding. Other studies have suggested that biophysical models of larval growth and survival should additionally include light attenuation, irradiance (Fiksen et al., 1998) as well as predation on larval fish.

Coupled biophysical models that consider the spatial heteorogeneity in environmental conditions by coupling larval trophodynamic IBMs to three-dimensional models have been established, for example, for Georges Bank cod (Werner et al., 1996). In their approach, losses from the system can be either due to advective processes or due to mortality caused by starvation. Fig. 12 shows an example, where 'on-bank' was defined as positions shallower than $100 \mathrm{~m}$ and east of a specific longitude $\left(69^{\circ} \mathrm{E}\right)$. A $10 \%$ 'off-bank' was already observed at hatch followed by an increase in 'off-bank' losses of larvae to the deep-ocean area with almost $20 \%$ of the total number of larvae spawned on the bank lost by day 40 post-spawn. Variability in their feeding success, growth and survival was calculated on the basis of spatial heteorogeneity of available prey, as well as turbulence that affects larval fish-prey encounter rates (e.g., Rothschild and Osborn, 1988; MacKenzie et al., 1994). In this example, the specified abundance and three-dimensional distribution of larval prey was insufficient for the survival of cod larvae. It took 2-3 days for the

(A)

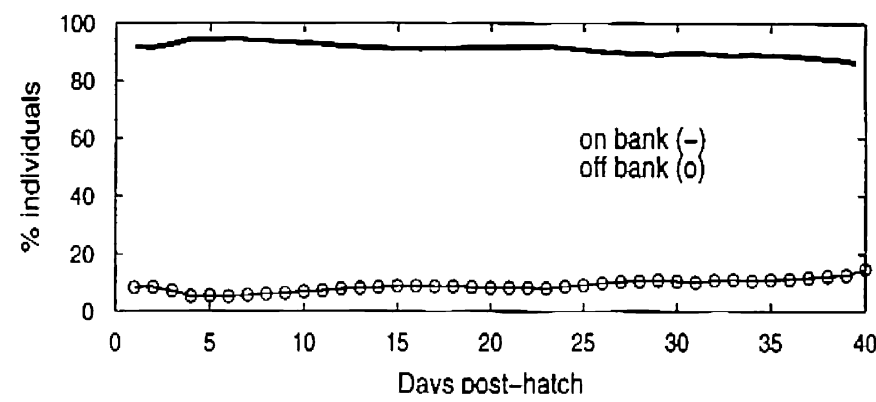

(B)

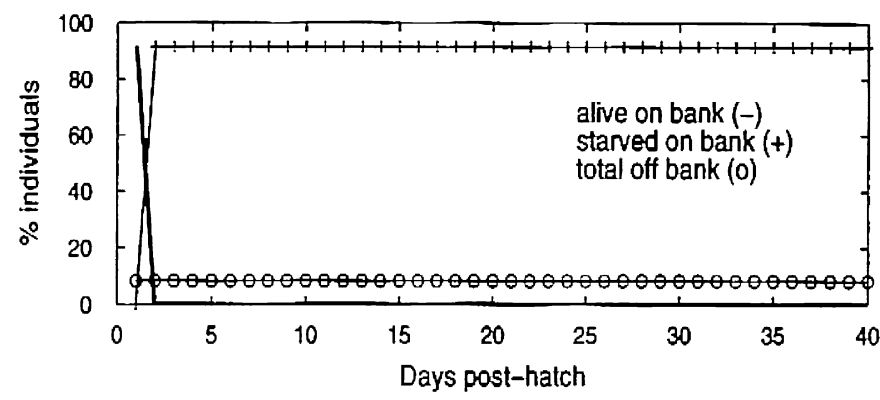

Fig. 12. (A) Effect of advection on the post-hatch time history of cod larvae onbank (solid line) and off-bank (solid line with open circles) At hatch, $10 \%$ of the eggs spawned on the bank have been lost off-bank; at day 40 post-hatch there is an additional $5 \%$ loss of larvae, resulting in a total loss due to advection of approximately $15 \%$, and (B) post-hatch time history of cod larvae in the deterministic case showing the percentage of larvae alive (solid line), starved on-bank (solid line with crosses), and advected off the bank (solid line with open circles; Werner et al., 1996). larvae that hatched at a mean size to reach a limiting weightdependent death barrier.

For the Baltic Sea, a coupled hydrodynamic-trophodynamic individual-based model of drift and feeding of larval cod (Gadus morhua L.) was employed to analyse the intra- and interannual variability in growth and survival (Hinrichsen et al., 2002). The sensitivity of growth and survival was studied by modeling the fate of larvae for spatial and temporal differences in food abundance and temperature as well as for various scenarios in prey fields. For example, the model was used to evaluate the impact of the observed declining standing stock of the main prey component of larval cod in the Baltic Sea, the calanoid copepod P. elongatus. Results indicated that when prey fields were defined to lack this copepod species, larvae released as Lagrangian drifters at the outer edge of the deep Bornholm Basin area (main reproduction area of Baltic cod) had considerably higher survival rates (20\%), likely because of their lower drift distances towards optimal feeding environments in more shallow coastal areas (Fig. 13), which are known to provide more beneficial feeding conditions for the larvae. In contrast, larvae hatching within the deep area of the Bornholm Basin during their firstfeeding stage experienced insufficient prey for survival along their onshore-oriented drift trajectories. A similar analysis performed for prey fields, including $P$. elongatus revealed no areas within the deeper part of the basin, led to significant starvation mortalities. As a validation step for the coupled biophysical model results, the time series of recruits of Baltic cod at age 2 obtained from virtual population analyses (VPA; ICES, 2001) in relation to egg production at stage III (Köster et al., 2001) were compared with the corresponding simulated larval survival (1986-1997). Egg production at this stage was considered to be representative for the early larval stage. The comparison of the ratio of observed recruitment and egg production with the biophysical model results revealed a strong significant correlation $(r=0.78)$. Recruitment of Baltic cod during the last decade depended on the production of late hatched larvae as the main spawning season has successively changed from spring to summer months (Wieland et al., 2000).

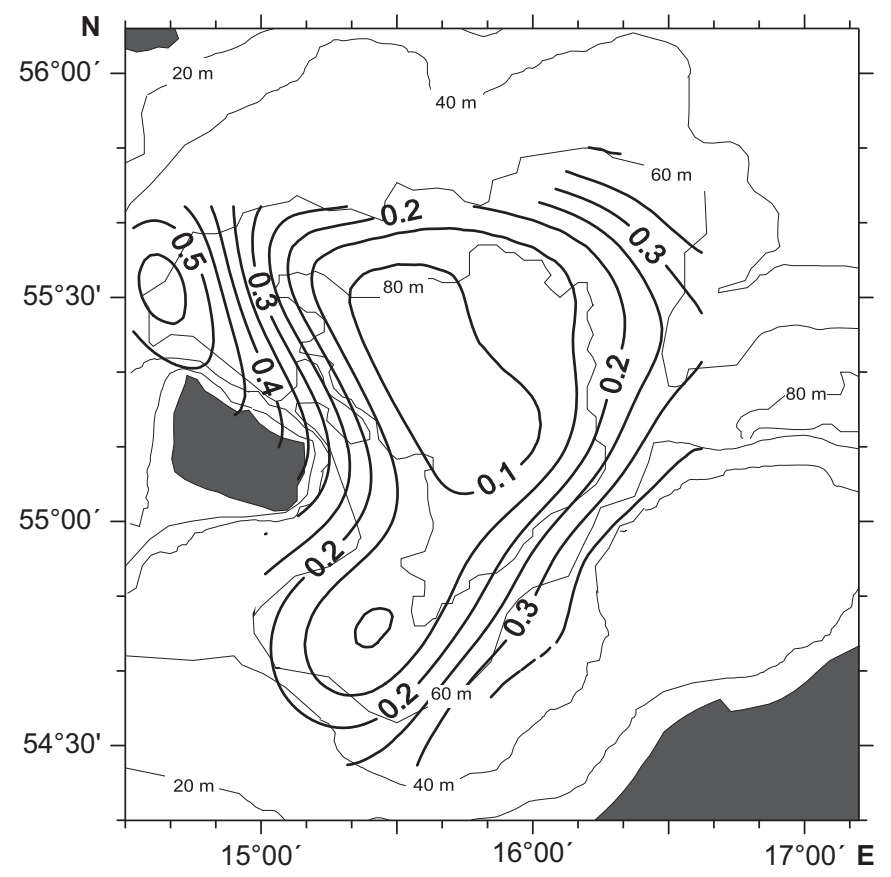

Fig. 13. Average (1986-1999) horizontal distribution of mean larval survival probability in the Bornholm Basin obtained from simulations without Pseudocalanus elongatus and without turbulence (Hinrichsen et al., 2002). 
Thus, variability of the abundance of $P$. elongatus has, in this time period, most likely, only a limited impact on larval survival, depending to a higher extent on the availability of other copepod species. Generally, larval survival is strongly influenced by transport into favourable feeding environments and thus depends on hydrographic and meteorological forcing conditions. Furthermore, this study demonstrated that retention and dispersal of early life stages can have detrimental as well as beneficial effects on larval survival depending on seasonal specific prey availability.

Biophysical models are critically influenced by hydrodynamic model predictions. Therefore, basic improvements in understanding of turbulence and in predicting mixing and circulation patterns will advance the field of larval fish modelling. Fundamental information is needed on the biological processes of mortality, behaviour and energetics to advance models of fish early life. These stage-dependent, and often species-specific, processes pose challenges for investigation; however, recent advances in field and laboratory techniques will likely revolutionize the field of larval fish modelling (Gallego et al., 2007). Furthermore, for many zooplankton as well as fish species, process information is lacking on factors that control their spatial and temporal patterns. Future work on model validation as well as the rigorous assessment of the level of confidence in the model predictions is crucial for any model that will be used for practical applications (Hannah, 2007). There is a need to incorporate for instance data into biophysical models generated by monitoring programmes and even influence their design so that they generate the measurements that are useful to parameterize and validate biophysical models (Gallego et al., 2007).

\section{Migration and habitat utilization}

When studying living organisms, modeling exercises might be complicated by the individual behaviour of the study organisms. Thus, a recurring point of criticism regarding these types of studies is the potential influence of swimming ability, especially as individuals grow bigger over time. The onset of active movement can be used to demarcate the end of the period when individual-based models on, e.g., larval drift and feeding can be used reliably. It also presents an individual's life stage at which many correlations between, e.g., distribution and environmental parameters can breakdown.

The spatial and temporal distributions of many fish species change in fairly regular and cyclical patterns. The adaptive value of fish migration is strongly coupled with the surrounding habitat. The reduction of the impact of environmental variance, for example, on reproductive success, competition for food, growth and survival are the benefits of survival (Aro, 1989). The extent of marine fish species distributions is determined by a number of different abiotic conditions such as temperature, salinity and current velocity, which together define the habitat to which a species physiology is suited. Observation of the in situ behaviour of individual fish is difficult and usually constrained to only short periods. Threshold levels of physical environmental variables often form the physiological preferences for the distribution of adult fish as well as for their early life stages. For example, a categorical approach combining data sets that contain a considerable number of spatial egg distributions as well as directed experiments with correspondingly measured physical environmental data provided a possibility to evaluate the spawning habitats of fish species (Hinrichsen et al., 2007a).

Reconstructing individual fish migration tracks enabled new insights into fish behaviour, for example, multi-year homing of Atlantic cod to a spawning ground at the Newfoundland coast
(Robichaud and Rose, 2001), timing of North Sea cod migrations (Turner et al., 2002) or selective tidal transport of North Sea demersal fish (Arnold and Holford, 1995). Habitat choices of adult fish can be tested with results from electronic data storage tags or with hydroacoustic data. Statistical analyses could test the hypothesis that fish are randomly distributed within habitats with regard to physical environmental variables or if they express significant habitat choices. Such characterization would allow the identification of processes or parameter, which is likely to alter the size and/or quality of, e.g., the reproduction volumes and adult habitat choices of fish species.

The advent of data storage tags now makes it feasible to resolve horizontal and vertical movements of marine fishes, and by integrating these movements with environment data, more fully understand the relationship between fish and physical measures of habitat. However, without geolocation, data storage tags can only describe the environmental experiences of individual fish. Thus, while data storage tags are very useful in observing what physical environment individuals chose, they do not record environments individuals have selected among others. This inevitably leads to the question whether a fish is behaving in response to the environmental conditions, or are the data storage tag data simply a reflection of changing ambient conditions. However, the addition of geolocation greatly expands the utility of data from archival tags.

A geolocation methodology presented by Neuenfeldt et al. (2007) is based on combined data of pressure, temperature and salinity obtained by tags attached to adult Baltic cod and hydrographic property fields obtained from hydrodynamic modelling. The model output was used as a geolocation database to identify individual pathways of Baltic cod by comparison with physical environmental data (temperature and salinity) collected by each tagged fish. Pressure, temperature and salinity records from individual tags indicated whether cod were stationary or moving, and whether fish migrated into the deep centre of a Baltic Basin. Subsequently, physical information on pressure, temperature and salinity were converted to oxygen saturations in order to test the hypothesis that cod in the Baltic Sea move into hypoxic waters (Neuenfeldt et al., 2008). The movements of tagged cod in 2003 shown in Fig. 14 are characteristic of eastern Baltic cod during the spawning season (Aro, 1989; Wieland et al., 2000). In the Bornholm Basin, there are frequent periods of anoxic conditions near the bottom, such that cod are unable to reach the bottom. The lack of oxygen in the bottom area will likely result in spawning elsewhere, e.g., higher levels in the water column as well as the basin slopes or the western Baltic Sea. However, during years exhibiting vertical oxygen saturation gradients as well as a lack of oxygen at the bottom, the frequency of residence times at or below given oxygen saturation showed that the maximal residence time in hypoxic water is limited (Fig. 15), but increases with oxygen saturation until reaching a constant level at oxygen conditions, which are known from laboratory experiments not to limit cod activity (Plante et al., 1998). The limited amount of time individual cod were present at low oxygen levels indicates vertical migration for feeding purposes, because high concentrations of adult sprat as their major pelagic prey item were observed at very low oxygen levels down to ca. $10 \%$ saturation. Comparison of cod distributions as revealed from tag data with distribution patterns obtained from hydroacoustic measurements showed similar patterns. Regarding hydroacoustic measurements, a categorical quotient analysis revealed a clear and significant avoidance of oxygen concentrations below $10 \%$ saturation, whereas oxygen concentrations between $40 \%$ and $60 \%$ saturation were positively selected (Schaber et al., 2008).

Generally, important future research objectives in this area include as follows: describing migratory pathways and seasonal 

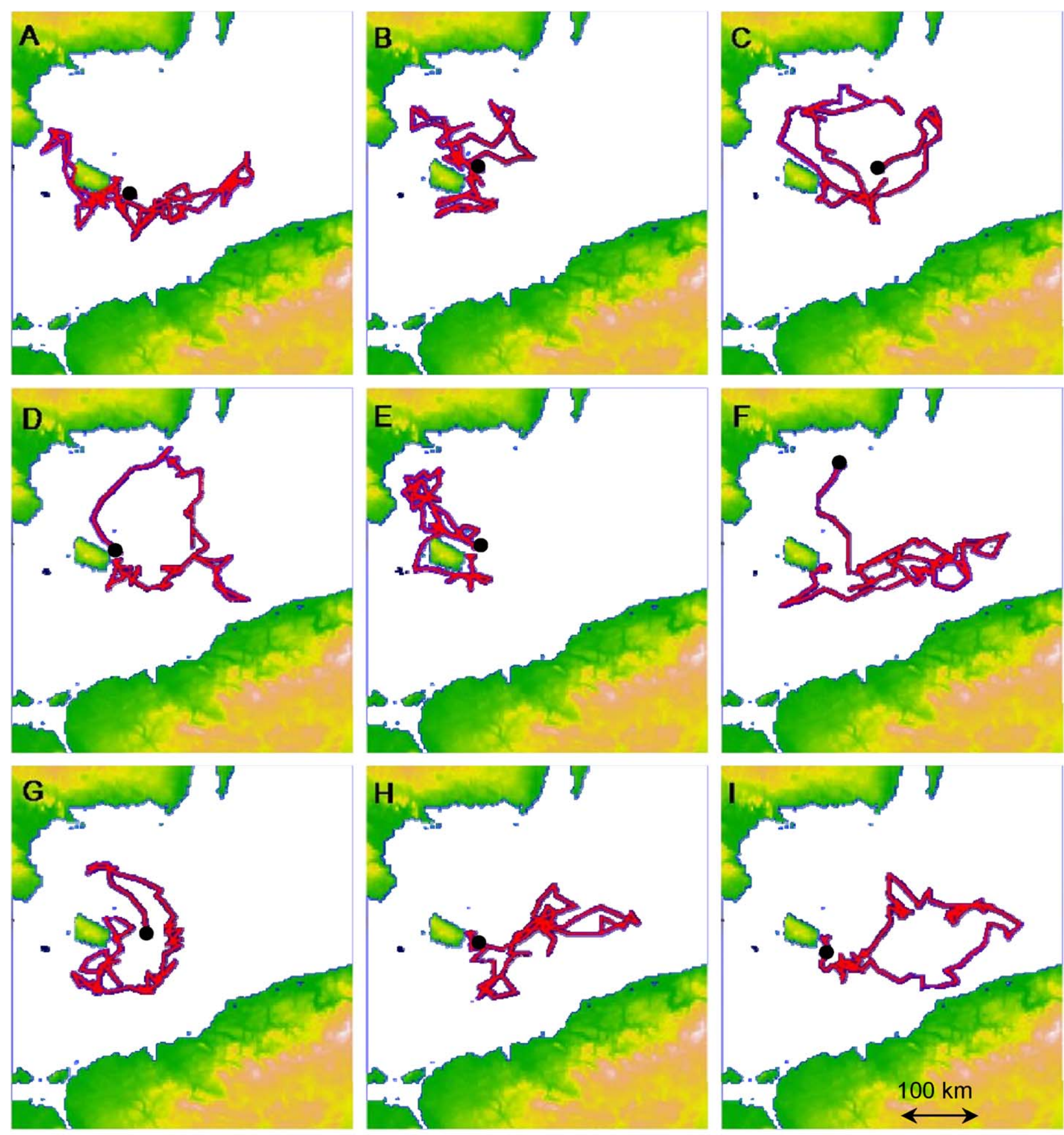

Fig. 14. (A-I) Estimated tracks from recaptured Baltic cod in 2003. Black dots indicate the recapture positions (Neuenfeldt et al., 2007).

changes in vertical and horizontal distribution; describing and understanding the functions of vertical migration. Major technical challenges are posed by determining geographical location, identifying the ambient water-mass characteristics of individual fish, and recording orientation and swimming speed. Furthermore, physiological measures of condition and reproductive state are also highly desirable. Presently, habitat envelopes that fish can occupy are not well known because most observations of, e.g., thermal preferences have been made in the laboratory. However, future large-scale electronic tagging programmes will have the potential to quantify and describe the temperature and depth experience of wild living fish and will hopefully allow to identify extremes that individual fish tolerate, and have the ability to assess the effects of temperature on growth and activity. For instance, future tagging programmes might help to reduce the relative lack of information of the tolerances and preferences of fish populations, and how they vary across their ranges. These informations could be of valuable use for the development of 
(A)

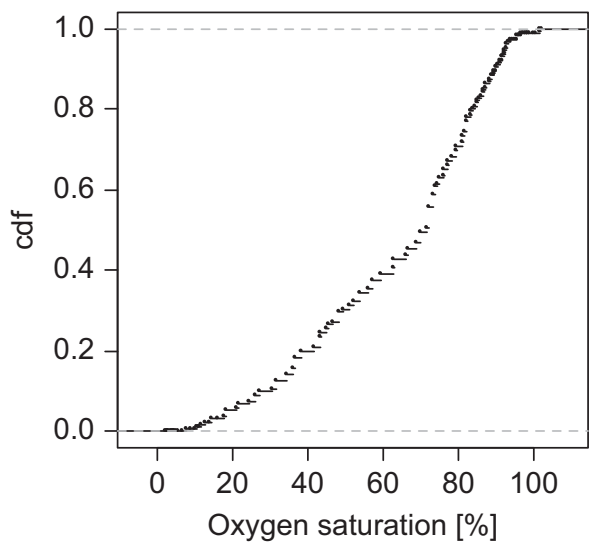

(B)

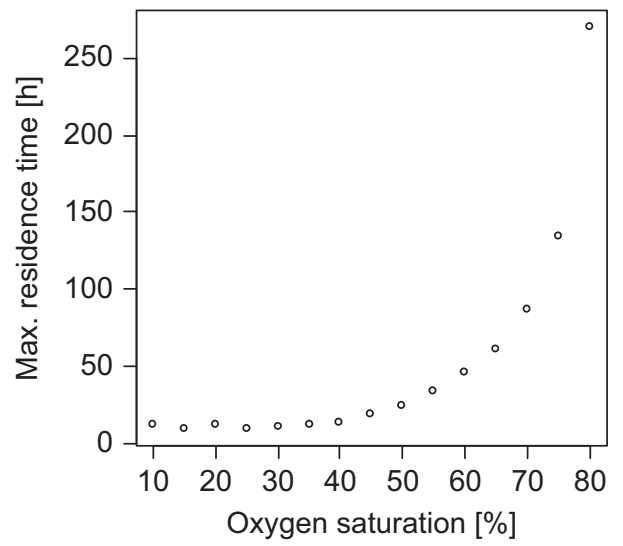

(C)

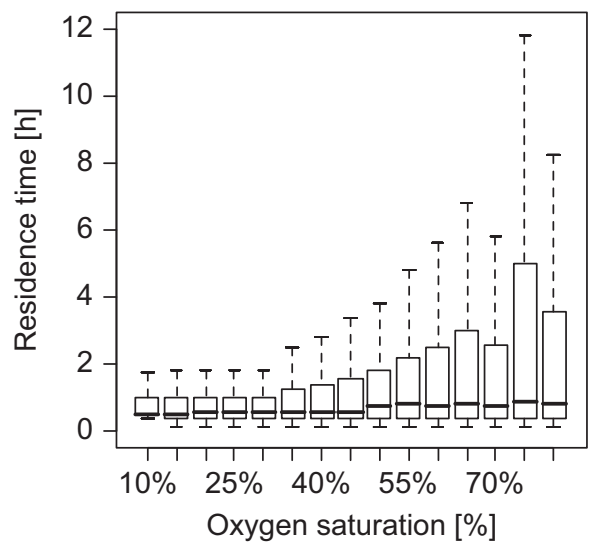

Fig. 15. Residence time at different oxygen saturations. The cumulative time spent at given saturation (Panel A) shows that the cod spent $20 \%$ of their total time below $40 \%$ oxygen saturation. However, single visits in hypoxic conditions, i.e., in saturations below $40 \%$ saturation were limited to a couple of hours at maximum (Panel B; the $y$-axis displays the $99 \%$ percentiles of the distributions of residence time at different oxygen saturations). This apparent discrepancy can only be explained, if cod undertake the short visits into hypoxia frequently. A critical saturation is 30\% (Panel C). Below 30\% oxygen saturation, neither the third quartiles (upper edges of boxes) nor the extreme residence times increase (upper whiskers extend to the most extreme data point, which is no more than 1.5 times the interquartile range from the box). Another critical saturation is 65\% (Panel C). Above 65\% oxygen saturation, the third quartiles and extreme residence times tend to stop increasing at further increasing oxygen saturation, indicating that above this level, maximal residence time is independent of oxygen saturation, at least on the time scale of this analysis (Neuenfeldt et al., 2008).

accurate predictive models of distribution and abundance, which are increasingly important as fish stocks decline and the effects of climate change on ocean temperatures begin to increase their impact.

\section{Predictability of biological processes by utilizing physical factors}

At the present stage, the need for examination and diagnosis of coupled biophysical processes is more important and more appropriate rather than to forecast them. However, in some cases, physical ocean parameters were identified, which could be utilized to perform short- to medium-term ecologically based process predictions. These predictions are possible if factors (e.g., climate, hydrography, recruitment) are consistent over long time periods. Correlational studies are useful means to detect long-term trends and general relationships between environmental variables and variability in the population dynamics of zooplankton and fish stocks, which are, for instance, instrumental for hypothesis generation (e.g., Ottersen et al., 2006).

The objective of this section is to quantify relationships between sprat egg survival and ambient temperature as well as between sprat recruitment and larval transport as environmental factors in the Baltic Sea ecosystem. These examples will demonstrate how such relationships can potentially improve forecast methodology. The interannual variability of copepod abundance and biomass in the Baltic was shown to depend on a large extend on thermal conditions controlled by climate factors (e.g., Dippner et al., 2000; Hänninen et al., 2000; Möllmann et al., 2003).

Distribution and intensity of vertical exchange is the key to many processes affecting physical as well as biological processes in stratified ecosystems like the Baltic Sea (Shaffer, 1979). It is more common to consider exchange across and along isopycnal surfaces rather than vertical and horizontal exchange since density stratification forms a barrier for fluid exchange. Mixing across isopycnal surfaces can only occur if sufficient energy exists to overcome the potential energy of the density stratification, i.e., cooling of sea-surface temperatures increases the density of the

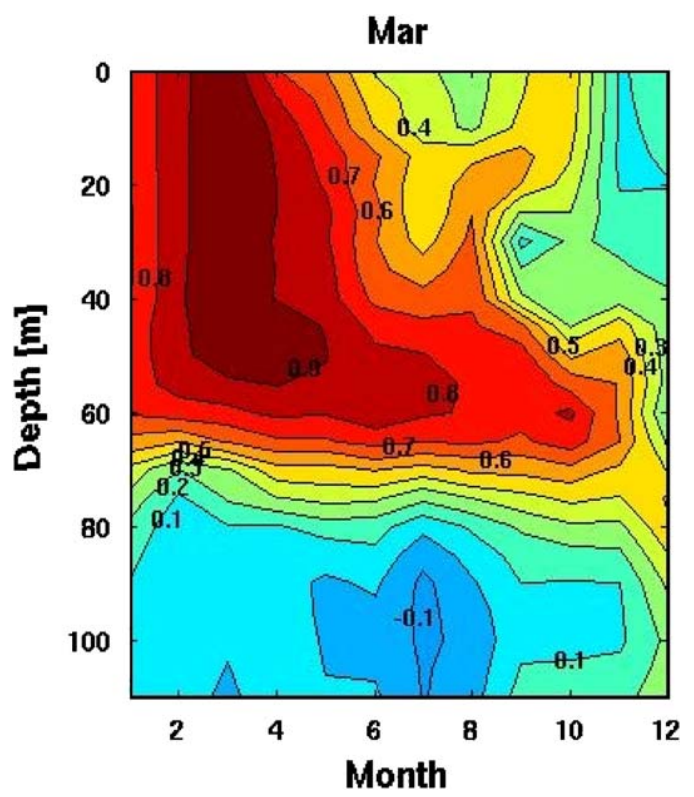

Fig. 16. Correlation coefficients between March sea-surface temperatures and deeper water-mass temperatures for all months of a year in the Gotland Basin (Hinrichsen et al., 2007b)

surface layer and reduces the energy required for mixing. During autumn and winter, cooling of the surface triggers vertical convection, thus cross-isopycnal mixing occurs until the temperature of the density maximum is reached.

Monthly mean temperatures at various depths in many areas of the Baltic Sea are significantly associated with the severity of the previous winter. The interaction between the temporal evolution of water-mass formation according to discrete monthly mean temperature values at the sea surface can be facilitated by the use of simple linear regression models (Hinrichsen et al., 2007b). Fig. 16 shows the temporal distribution of correlation coefficient values of the cross-correlation between SST for March and corresponding temporally and vertically resolved temperature data for the Gotland Basin. 
The assessment of the long-term development of Baltic Sea temperatures reveals significant positive trends. The interannual variability of winter water-mass temperatures are similar to those of the SSTs, i.e., the thermal conditions between 40 and $60 \mathrm{~m}$ for May and July show a regime shift like increase in temperature $\left(1-1.5^{\circ} \mathrm{C}\right)$.

The impact of temperature on survival of sprat eggs (Nissling 2004; Petereit et al., 2008) was calculated on the basis of average ambient temperatures $(40-60 \mathrm{~m})$ in the Bornholm Basin at main spawning time in May as well as on predictions based on mean SSTs recorded during March. Extremely low-temperature-dependent egg survival (Fig. 17A) has been associated with severe winters accompanied by low water temperatures during peak spawning (1979, 1985-1987). In this respect, the absence of severe winters since the middle of the 1980s indicates favourable thermal conditions for sprat egg survival and most likely contributed to the generally high recruitment (Köster et al., 2003). Fig. 17B and C shows the generation times of Acartia spp. and Pseudocalanus acuspes in July and May. Because of the high variability in the winter water mass, the time series exhibit strong variations in the developmental times of the copepods. Especially for Acartia spp. the potential generation time varied between 50 and 150 days, while the thermal effect on stage development was less pronounced for P. acuspes (50-100 days). Generally, the
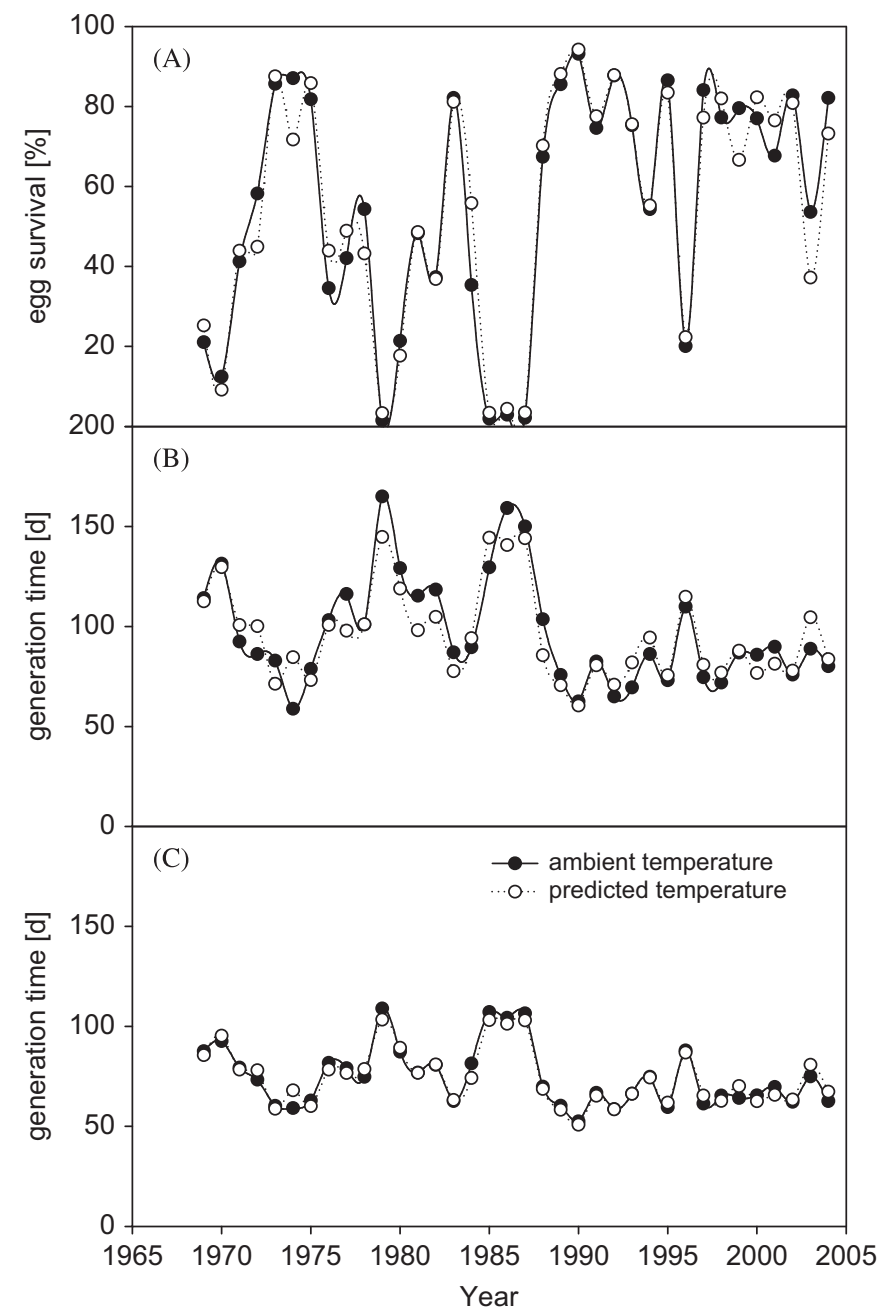

Fig. 17. Time series of temperature-dependent rate processes in the Bornholm Basin: (A) sprat egg survival, (B) generation time of Acartia spp. and (C) generation time of Pseudocalanus acuspes (Hinrichsen et al., 2007b). coincidence between observed and predicted temperaturedependent rate processes is quite high. These exercises resulted in up to more than $90 \%$ explained variance between temperaturedependent rate processes derived from observations and predictions.

Baumann et al. (2006) presented a drift index to explain sprat recruitment variability within the entire Baltic Sea over a time series of 25 years (1979-2003). The index was based on hydrodynamic modeling in conjunction with Lagrangian particle simulations. Instead of analysing final horizontal drifter positions, integration of the entire drift period by considering the average water depth across all daily particle positions as a proxy of larval transport from the deep spawning basins to the coast was performed. The underlying rationale was that years of predominant larval retention or coastal transport should result in anomalously deep or shallow particle distributions, respectively. Years of strong larval displacement towards southern and eastern coasts corresponded to relative recruitment failure, while years of retention within the deep basins were associated with relative recruitment success. The drift index was significantly correlated to sprat recruitment success and explained, together with sprat spawning stock biomass, $82 \%$ of the overall variability (Fig. 18). The approach advocates that new year classes of Baltic sprat are determined in strength mainly by processes acting during the late larval and early juvenile stages.

Here, relationships among environmental factors, spawner biomass and recruitment of Baltic sprat were used to simulate how the sprat population might react to exploitation and to variability in atmospheric forcing. Comparing observed and simulated recruitment (Fig. 18) revealed that this approach was able to predict with a high degree of confidence the high variability of sprat recruitment in the Baltic. Relatively low levels of recruits were obtained for the 1980s, while a strong increase of recruitment was observed from the 1990s onwards. However, prior to be included into recruitment predictions, the biological mechanisms underlying this strong correlation need to be better resolved.

Although, in some cases, predictable physical components of the ocean system have been identified, presently, appropriate diagnosis of coupled biophysical processes is generally more important than predictability. In future times, state-of-the-art tools such as circulation models or more complex coupled individual-based model should be employed together with data

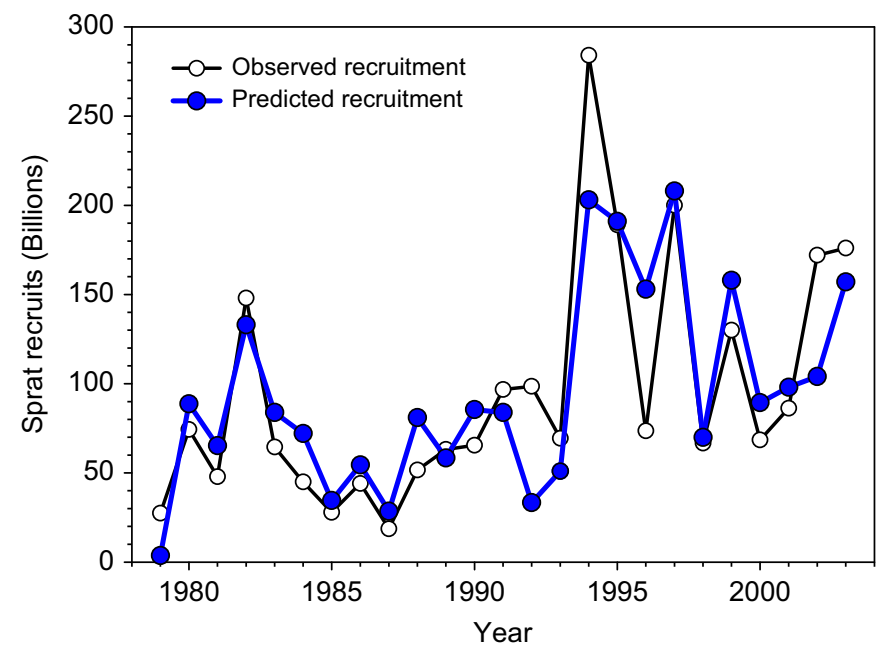

Fig. 18. Time series of observed and predicted Baltic sprat (Sprattus sprattus) recruitment (Baumann et al., 2006). 
mining and retrospective analysis of available data to better understand the variability of the interaction between physics and biology. In this respect, the ability of such methods or tools to properly downscale from the large to regional scale capable of resolving mesoscale features such as the scales of the ocean's continental shelves will be of general importance in future. Besides the utility of complex coupled biophysical models, ecosystem-oriented predictions, e.g., recruitment models, should move towards limiting increases in complexity. Approaches in which numerical models disappear entirely so that predictions are based, e.g., on observational indices whose causal links to biology were established using both observational analysis and numerical modelling are highly recommended (Hannah, 2007). The approach of limiting complexity has the advantage of a reduced need for data and has the ability for quantitative validation and hypothesis testing.

\section{Discussion}

Relationships between physical data and changes in ecosystem processes have routinely been identified, but the specific mechanisms involved are usually unclear. There might be a number of reasons for this: the ecosystem can be contemporaneously influenced by many physical variables; the ecosystem can be very sensitive to the seasonal timing of the physical forcing; and the ecosystem can generate intrinsic variability on climate time scales. Limited observation of both the physics and the biology may also confound these various interpretations. In addition to purely statistical comparisons of physical and biological variables, there is a need to develop model-based approaches. The use of models, such as coupled biophysical models, would help to increase the understanding of the processes or mechanisms underlying the statistical relationships. Furthermore, models permit the incorporation of additional data from different disciplines, and help to define and to improve the questions being asked of the data.

As recently obtained from a variety of examples, studies of fish recruitment processes have often focused on correlations among environmental factors, stock characteristics and recruitment levels or, alternatively, on single processes occurring at the level of individual organisms or single life stages, for example, mortality or starvation. It is now generally accepted that a variety of mechanisms operating on different temporal and spatial scales may be important and that overall recruitment levels are unlikely to be controlled by a single factor, process, or life stage (e.g., Rothschild, 2000). The mechanisms by which physical forcing affects biological processes in marine ecosystems range from those associated with small scale of dissipation, turbulent mixing and diffusion to those acting on the mesoscale associated with fronts, eddies and upwelling, to those predominating on basin scales. Physical data must have a high enough spatial and temporal resolution to be able to resolve critical processes. The physical forcing on biology can occur instantaneously or with a time delay, whereby climate forcing apparently appears to act on ecosystems in both linear and non-linear ways. The most critical limitation of biological data is the poor knowledge on processes related to them. Biological rate processes are mainly available as mean values, while information on the variability of biological rate processes is seldom presented. The challenge is to understand the underlying mechanisms of the responses to instantaneous and delayed physical environmental changes.

The coupling of hydrodynamic models, for example, with trophodynamic relationships for larval fish can be utilized to examine starvation mortality and growth rates at the level of individual larva as well as estimating larval losses from ecosystems. Generally, hydrodynamic models using either Lagrangian particle tracking (e.g., Werner et al., 1993; Hinrichsen et al., 1997) or advection-diffusion equation models (Lynch et al., 1998) resolve the small-scale vertical and mesoscale horizontal variability of the hydrodynamics quite well. Although circulation patterns are relatively well known, validation of the results of coupled biophysical model approaches is difficult. Variations in particle transport and hence horizontal distribution of pelagic and demersal stages of zooplankton species and juvenile fish can be caused by intra- as well as interannual variations in meterorological forcing, temperature, light intensity, river runoff, turbulence, frontal structure, sea-level gradients, hydrographic property fields and surface heat fluxes. Although conceptually appealing, verification of the effect of transport on recruitment success is difficult for various reasons, such as a lack of recruitment time series, problems in identifying spawning and nursery areas or accurate quantification of the reproductive effort. The dominant biological limitations to adequate modeling of transport of individuals are their vertical distribution and the timing and location of spawning and hatching. Mainly because of the lack of suitable field-based biological data, validation of the biological components of these kinds of coupled models seems to be more critical. Trophodynamics are the most difficult processes implemented in models of larval growth and survival because of the difficulties in validating such models experimentally or with data obtained during field programs. In general, coupled biophysical models examining the effects of larval feeding on growth and survival have to cope with a relatively sparse temporal and spatial resolution of prey fields. Other processes which potentially need to be addressed are larval behaviour as a function of larval size and predation as a process influencing the abundance of larvae in a system.

The key to prediction and understanding of coupled biophysical processes lies in the elucidation of mechanisms underlying observed patterns. Typically, these mechanisms operate on scales different to those on which the patterns are observed; in some cases, the patterns must be understood as emerging from the collective behaviours of smaller-scale units. In other case, the pattern is imposed by larger-scale constraints. Examination of such phenomena requires the study of how pattern and variability change with the scale of description, and the development of laws for simplification, aggregation and scaling (Levin, 1992). Although the biological components of coupled biophysical models often tend not to be very useful in a predictive sense, they are extremely useful components as intuition building tools for scientific investigations. They are inexpensive compared to field observations and they provide virtual environments that can be used to follow experimental designs and are a valuable tool to run controlled experiments and scenarios. Advanced models may be very useful tools for hypothesis testing, and for sensitivity analyses to help identify those processes that are important and would most benefit from further field studies. Laboratory experiments would also contribute towards this. However, longer simulation runs will provide increasing uncertainties in the modelled property fields. These uncertainties arise from errors in the specified forcing, boundary and initial conditions, and subgrid scale physical processes not resolved by the model dynamics. To overcome at least some of these problems the utilization of assimilation techniques may become important for long-term simulations. However, sensitivity studies have demonstrated that coupled biophysical models are sensitive enough to show the effects of parameter uncertainty (e.g., Kendall et al., 1987) and to demonstrate the impact of natural perturbation (e.g., Campana et al., 1989), especially in encounter and starvation processes. 


\section{Final remarks}

To investigate the importance of different coupled biophysical processes this manuscript is mainly focused on ecosystem processes in the Baltic Sea. The hydrographic conditions in the central Baltic Sea during the last three decades, with mainly high values of NAO, were affected by large-scale climatic conditions. This resulted in above-average water temperatures in the Baltic Sea. In addition, increased river runoff and precipitation reduced the probability that inflows of highly saline and oxygenated water from the North Sea could be advected to, and re-oxygenate, the deep water of the Baltic Basins (Matthäus and Nausch, 2003).

In the Baltic Sea, since the middle of the 1980s, cod and sprat as the ecologically and economically most important fish species have shown strong asynchronie between the spawning stock biomass and their surviving offsprings. For example, linear regression analyses revealed only weak but significant relationships between spawning stock biomass and recruitment of cod and sprat (Köster et al., 2003). This is an ultimate sign that fish stock variations are not only affected by fishing effort but is also driven by environmental conditions. For this reason, investigations of the link between long-term climate variability, spawning stock features and reproductive success of cod and sprat have been performed. The changing environmental conditions and as a consequence the changing recruitment success for the two species in combination with high fishing pressure on cod and low predation pressure on sprat caused a 'regime shift' in the second half of the 1990s from a cod- to a sprat-dominated system (Köster et al., 2003). Clearly the ecosystem of the Central Baltic Sea changed from a state of high productivity for the cod stock, characterized by climatically driven high salinity/oxygen conditions and low temperatures, to a state of high productivity for the sprat stock, characterized by low salinity/oxygen conditions and high temperatures. For Baltic cod, the period between the late egg and the early larval stage is critical for recruitment. A potential variable identified to affect this life stage was the environmentally driven decline of appropriate prey for first-feeding larvae (Hinrichsen et al., 2002; Köster et al., 2003). For sprat, year-class strength was largely independent of larval abundance but the period between the late larval and early juvenile stage appeared to be critical for recruitment (Baumann et al., 2006). Ambient temperature and wind stress were identified as the most important environmental factors, which had an impact on recruitment success of Baltic sprat.

For modelling purposes it was a great advantage that in the Baltic the initial spawning locations and habitats for eggs and early larvae of cod and sprat were well known. Thus, e.g., coupled biophysical models are able to predict climatically driven spatial and temporal patterns of recruitment success, because the necessary input data on spatially and temporally resolved egg production data were made available in the Baltic for the last three decades. Hence, in dependency on the seasonal as well as on the long-term variability of wind-induced ocean currents, the model was able to determine how recruits were distributed in space and time, i.e., environmentally driven early life stage survival rates could be calculated and could be linked to variations in the long-term recruitment success of Baltic cod and sprat (Hinrichsen et al., 2002; Baumann et al., 2006). Additionally, because of differences in the vertical distribution of larval Baltic cod and sprat, between species variability in long-term transport patterns could be identified as the flow is not vertically homogeneous. As a consequence, in the Baltic, models have been utilized that allow to identify long-term variations in the location of nursery areas of Baltic cod and sprat (Hinrichsen et al., 2006). As an example, the initial distinct horizontal distribution patterns of eggs and early larvae of Baltic cod and sprat as well as the within and between year variability of the wind-induced circulation patterns provided by a hydrodynamic model exercise facilitated both the existence of self-sustaining populations of Baltic cod and sprat and the regions of mixed recruitment of stock components of different origin (Hinrichsen et al., 2001, 2006). However, the availability of long-term climate data time series for the entire Baltic Sea area provides the unique opportunity to evaluate whether climate change may alter patterns of connectivity between regional subpopulations of the Baltic cod and sprat stock.

The Bornholm Basin is one of the best known closed major spawning grounds for cod and sprat, with a large number of historic survey data as well as material from ongoing investigations being available. Together with long-term climatic atmospheric forcing data this extensive database allowed to investigate quantitative influences of advective losses, uncertainty due to non-sufficient spatial sampling resolution (e.g., number of stations) and effects of the sampling strategy (e.g., sequence of stations) on abundance estimates of cod and sprat early life stages (Voss and Hinrichsen, 2003). Generally, the results suggest that climate data such as wind forcing might serve as a first rough approximation for the reliability of historic abundance estimates.

\section{Acknowledgements}

The work was conducted under the frame of the GLOBEC Germany project, with financial support from BMBF and the EU-funded projects UNCOVER, PROTECT and BECAUSE. I thank M. Peck from the University of Hamburg, Germany, for the permission to present the schematics of the Individual-Based model on larval feeding, growth and survival.

\section{References}

Alheit, J., Möllmann, C., Dutz, J., Kornilovs, G., Löwe, P., Mohrholz, V., Wasmund, N., 2005. Synchronous ecological regime shifts in the North and Central Baltic Sea in 1987-88. ICES Journal of Marine Science 62, 1205-1215.

Allain, G., Pettigas, P., Grellier, P., Lazure, P., 2003. The selection process from larval to juvenile stages of anchovy (Engraulis encrasicolus) in the Bay of Biscay investigated by Lagrangian simulations and comparative otolith growth. Fisheries Oceanography 12, 407-418.

Arnold, G.P., Holford, B.H., 1995. A computer simulation model for predicting rates and scales of movement of demersal fish on the European continental shelf. ICES Journal of Marine Science 52, 981-990.

Aro, E., 1989. A review of fish migration patterns in the Baltic. Rapport ProcèsVerbal de la Reunion. Conseil Permanent International pour l'Exploration de la Mer 190, 72-96.

Baumann, H., Hinrichsen, H.-H., Möllmann, C., Köster, F.W., Malzahn, A.M., Temming, A., 2006. Recruitment variability in Baltic sprat, Sprattus sprattus, is tightly coupled to temperature and transport patterns affecting the larval and early juvenile stages. Canadian Journal of Fisheries and Aquatic Science 63, 2191-2201.

Beaugrand, G., Reid, P.C., Ibanes, F., Lindley, J.A., Edwards, M., 2002. Reorganisation of North Atlantic marine copepod diversity and climate. Science 296, 1692-1694.

Borja, A., Uriarte, A., Egana, J., Motos, L., Valencia, V., 1998. Relationship between anchovy (Engraulis encrasicolus) recruitment and environment in the Bay of Biscay (1967-1996). Fisheries Oceanography 7 (3/4), 375-380.

Brett, J.R., 1979. Environmental factors and growth. In: Hoar, W.S., Randall, D.J., Brett, J.R. (Eds.), Fish Physiology, vol. 8. Academic Press, London, UK, pp. 599-675.

Browman, H.I., 1996. Predator-prey interactions in the sea: commentaries on the role of turbulence. Marine Ecology Progress Series 139, 301-312.

Campana, S.E., 1996. Year-class strength and growth rate in young Atlantic cod Gadus morhua. Marine Ecology Progress Series 135, 21-26.

Campana, S.E., Frank, K.T., Hurley, P.C.F., Koeller, P.A., Page, F.H., Smith, P.C., 1989. Survival and abundance of young Atlantic cod (Gadus morhua) and haddock (Melanogrammas aeglefinus) as indicators of year class strength. Canadian Journal of Fisheries and Aquatic Science 46, 171-182.

Cowan Jr., J.H., Shaw, R.F., 2002. Recruitment. In: Fuiman, L.A., Werner, F.E. (Eds.), The Unique Contribution of Early Life Stages. Blackwell Publishing, Oxford, 88-111pp. 
deYoung, B., Heath, M., Werner, F., Chai, F., Megrey, B., Monfray, P., 2004. Challenges of modelling decadal variability in ocean basin ecosystems. Science 304 $1463-1466$.

Dippner, J.W., Kornilovs, G., Sidrevics, L., 2000. Long-term variability of mesozooplankton in the Central Baltic Sea. Journal of Marine Systems 25, 23-32.

Dower, J.F., Miller, T.J., Leggett, W.G., 1997. The role of microscale turbulence in the feeding ecology of larval fishes. Advances in Marine Biology 31, 169-220.

Fiksen, O., Utne, A.C.W., Aksnes, D.L., Eiane, K., Helvik, J.V., Sundby, S., 1998 Modelling the influence of light, turbulence and ontogeny on ingestion rates in larval cod and herring. Fisheries Oceanography 7, 355-363.

Fonselius, S., Valderrama, J., 2003. One hundred years of hydrographic measurements in the Baltic Sea. Journal of Sea Research 49, 229-241.

Fortier, I.C., Leggett, W.C., 1985. A drift study of larval fish survival. Marine Ecology Progress Series 25, 245-257.

Fowler, A.J., Jennings, P.R., 2003. Dynamics in 0+ recruitment and early life history for snapper (Pagrus auratus, Sparidae) in South Australia. Marine Freshwate Research 54, 941-956.

Fromentin, J.M., Planque, B., 1996. Calanus and environment in the eastern North Atlantic. 2. Influence of the North Atlantic Oscillation on Calanus finmarchicus and Calanus helgolandicus. Marine Ecology Progress Series 134, 111-118.

Gallego, A., North, E.W., Pettigas, P., 2007. Introduction: status and future of modelling physical-biological interactions during the early life of fishes. Marine Ecology Progress Series 347, 121-126.

Hannah, C., 2007. Future directions in modeling physical-biological interactions. Marine Ecology Progress Series 347, 301-306.

Hay, D.E., McCarter, P.B., Daniel, K.S., 2001. Tagging of Pacific herring Clupea pallasi from 1936 to 1992: a review with comments on homing, geographic fidelity, and straying. Canadian Journal of Fisheries and Aquatic Science 58, 1356-1370.

Hänninen, J., Vuorinen, I., Hjelt, P., 2000. Climate factors in Atlantic control the oceanographic and ecological changes in the Baltic Sea. Limnology and Oceanography $45,703-710$.

Heath, M., 1992. Field investigations of the earlylife stages of marine fish. Advances in Marine Biology 28, 1-174

Heath, M., Gallego, A., 1998. Modelling the spatial and temporal structure of survivorship to settlement in North Sea and west of Scotland haddock. ICES CM 2000/N:11.

Heath, M., Gallego, A., 2000. Bio-physical modelling of the early life stages of haddock, Melanogrammus aeglefinus, in the North Sea. Fisheries Oceanography 7, 110-125.

Hermann, A.J., Rugen, W.C., Stabeno, P.J., Bond, N.C., 1996. Physical transport of young pollock larvae (Theragra chalcogramma) near Shelikof Strait. Fisheries Oceanography $5,58-70$.

Hermann, A.J., Hinckley, S., Megrey, B.A., Napp, J.M., 2001. Applied and theoretica considerations for constructing spatially explicit individual-based models of marine larval fish that include multiple trophic levels. ICES Journal of Marine Science 58, 1030-1041.

Hinckley, S., Hermann, A.J., Megrey, B.A., 1996. Development of a spatially explicit individual-based model of marine fish earlylife history. Marine Ecology Progress Series 139, 47-68.

Hinckley, S., Hermann, A.J., Meir, K.L., Megrey, B.A., 2001. Importance of spawning location and timing to successful transport to nursery areas: a simulation of Gulf of Alaska walleye pollock. ICES Journal of Marine Science 58, 1042-1052.

Hinrichsen, H.H., Lehmann, A., St. John, M.A., Brügge, B., 1997. Modelling the Cod larvae drift in the Bornholm Basin in Summer 1994. Continental Shelf Research $17,1765-1784$.

Hinrichsen, H.-H., Böttcher, U., Oeberst, R., Voss, R., Lehmann, A., 2001. The potential for advective exchange of the earlylife stages between the western and eastern Baltic cod (Gadus morhua L.) stocks. Fisheries Oceanography 10 (3), 249-258.

Hinrichsen, H.-H., Möllmann, C., Voss, R., Köster, F.W., Kornilovs, G., 2002. Biophysical modelling of larval Baltic cod (Gadus morhua L) growth and survival. Canadian Journal of Fisheries and Aquatic Sciences 59, 1858-1873.

Hinrichsen, H.-H., Kraus, G., Voss, R., Stepputtis, D., Baumann, H., 2006. The genera distribution of pattern and mixing probability of Baltic sprat juvenile populations. Journal of Marine Systems 58 (1-2), 52-66.

Hinrichsen, H.-H., Voss, R., Wieland, K., Köster, F., Andersen, K.H., Margonski, P., 2007a. Spatial and temporal heterogeneity of the cod spawning environment in the Bornholm Basin, Baltic Sea. Marine Ecology Progress Series 345, 245-254

Hinrichsen, H.-H., Lehmann, A., Petereit, C., Schmidt, J.O., 2007b. Correlation analyses of Baltic Sea winter water mass formation and its impact on secondary and tertiary production. Oceanologia 49 (3), 381-395.

Houde, E.D., 1987. Fish early life dynamics and recruitment variability. American Fisheries Society Symposium 2, 17-29.

Houde, E.D., 1989. Comparative growth, mortality, and energetics of marine fish larvae: temperature and latitudinal effects. Fisheries Bulletin US 87, 471-495.

International Council on the Exploration of the Sea (ICES), 2001. Report of the Baltic Fisheries Assessment Working Group. ICES CM 2001/ACFM:18.

Iles, T.D., Sinclair, M., 1982. Atlantic herring: stock discreteness and abundance. Science 215, 627-633.

Kendall Jr., A.W., Clarke, M.E., Yoklavich, M.M., Boehlert, G.W., 1987. Distribution, feeding, growth of larval walleye pollock, Theragra chalcogramma, from Shelikof Strait, Gulf of Alaska. Fisheries Bulletin US 85, 499-521.

Klein-Breteler, W.C.M., Schogt, N., 1994. Development of Acartia clausi (Copepoda, Calanoida) cultured at different conditions of temperature and food. Hydrobiologia 293, 469-479.
Klein-Breteler, W.C.M., Gonzalez, S., Schogt, N., 1995. Development of Pseudocalanus elongatus (Copepoda, Calanoida) cultured at different temperature and food conditions. Marine Ecology Progress Series 119 (1-3), 99-110.

Köster, F.W., Hinrichsen, H.H., St.John, M., Schnack, D., MacKenzie, B.R., Tomkiewicz, J., Plikshs, M., 2001. Developing Baltic cod recruitment models. Il Incorporation of environmental variability and species interaction. Canadian Journal of Fisheries and Aquatic Science 58, 973-984.

Köster, F.W., Möllmann, C., Neuenfeldt, S., Vinther, M., St.John, M.A., Tomkiewicz, J. Voss, R., Hinrichsen, H.-H., MacKenzie, B., Kraus, G. Schnack, D., 2003. Fish stock development in the central Baltic Sea (1974-1999) in relation to variability in the environment. ICES Marine Science Symposium 219, 294-306.

Köster, F.W., Möllmann, C., Hinrichsen, H.-H.S., Tomkiewicz, J., Wieland, K., Kraus, G., Voss, R., MacKenzie, B., Schnack, D., Makarchouk, A., Plikshs, M., Beyer, J.E., 2005. Baltic cod recruitment - the impact of climate and species interaction. ICES Journal of Marine Science 62, 1408-1425.

Lehmann, A., Hinrichsen, H.-H., 2000. On the thermohaline variability of the Baltic Sea. Journal of Marine Systems 25, 333-357.

Letcher, B.H., Rice, J.A., Crowder, L.B., Rose, K.A., 1996. Variability in survival of larval fish: disentangling components with a generalized individual-based model. Canadian Journal of Fisheries and Aquatic Science 53, 787-801.

Levin, S.A., 1992. The problem of pattern and scale in ecology. Ecology 73 (6), 1943-1967.

Limburg, K.E., 1996. Growth and migration of 0-year American shad (Alosa sapidissima) in the Hudson River estuary: otolith microstructural analysis. Canadian Journal of Fisheries and Aquatic Science 53, 220-238.

Lough, R.G., Smith, W.G., Werner, F.E., Lodere, J.W., Page, F.H., Hannah, C.G., Naimie C.E., Perry, R.I., Sinclair, M., Lynch, D., 1994. Influence of wind-driven advection on interannual variability in cod egg and larval distributions on Georges Bank: 1982 vs. 1985. ICES Marine Science Symposia 198, 356-378.

Lough, R.G., Buckley, L.J., Werner, F.E., Quinlan, J.A., Edwards, K.P., 2005. A general biophysical model of larval cod (Gadus morhua) growth applied to populations on Georges Bank. Fisheries Oceanography 14, 241-262.

Lynch, D.R., Gentlemen, W.C., McGillicuddy, D.J., Davis, C.S., 1998. Biological/ physical simulations of Calanus Finmarchicus population dynamics in the Gulf of Maine. Marine Ecology Progress Series 169, 189-210.

Lynch, D.R., Lewis, C.V.W., Werner, F.E., 2001. Can Georges Bank larval cod survive on a calanoid diet? Deep-Sea Research II 48, 609-630.

MacKenzie, B.R., Miller, T.J., Cyr, S., Leggett, W.C., 1994. Evidence for a dome-shaped relationship between turbulence and larval fish ingestion rates. Limnology and Oceanography 40, 1278-1289.

Mariani, P., MacKenzie, B.R., Visser, A.W., Botte, V., 2007. Individual-based simulations of larval fish feeding in turbulent environments. Marine Ecology Progress Series 347, 155-169.

Marshall, J., Kushnir, Y., Batisti, D., Chang, P., Czaja, A., Dickson, R., Hurrell, J.W. McCartney, M., Saravanan, R., Visbeck, M., 2001. North Atlantic climate variability: phenomena, impacts and mechanisms. International Journal of Climatology 21, 1863-1898.

Matthäus, W., Nausch, G., 2003. Hydrographic-hydrochemical variability in the Baltic Sea during the 1990s in relation to changes in the 20th century. ICES Marine Science Symposium 219, 132-143.

Möllmann, C., Köster, F.W., Kornilovs, G., Sidrevics, L., 2003. Interannual variability in population dynamics of calanoid copepods in the Central Baltic Sea. ICES Journal of Marine Science 219, 220-230.

Möllmann, C., Müller-Karulis, B., Diekmann, R., Flinkman, J., Kornilovs, G., LysiakPastuszak, E. Modin, J., Plikshs, M., Walther, Y, Wasmund, N., 2006. An integrated ecosystem assessment of the central Baltic Sea and the Gulf of Riga. ICES CM 2006/P, 03

Munk, P., 1993. Differential growth of larval sprat Sprattus sprattus across a tidal front in the eastern North Sea. Marine Ecology Progress Series 99, $17-27$.

Neuenfeldt, S., Hinrichsen, H.-H., Nielsen, A., Andersen, K.H., 2007. Reconstructing migrations of individual cod (Gadus morhua L.) in the Baltic Sea by using electronic data storage tags. Fisheries Oceanography 16 (6), 526-535.

Neuenfeldt, S., Hinrichsen, H.-H., Andersen, K.H., 2008. Atlantic cod Gadus morhuc L. in the Baltic Sea visit hypoxic water briefly but often. Journal of Fish Biology, in press.

Nissling, A., 2004. Effects of temperature on egg and larval survival of cod (Gadus morhua) and sprat (Sprattus sprattus) in the Baltic Sea-implications for stock development. Hydrobiology 514, 115-123.

Otterlei, E., Nyhammer, G., Folkvord, A., Stefansson, S.O., 1999. Temperature- and size-dependent growth of larval and juvenile Atlantic cod (Gadus morhua): a comparative study of Norwegian coastal cod and northeast Arctic cod. Canadian Journal of Fisheries Aquatic Science 56, 2099-2111.

Ottersen, G., Planque, B., Belgrano, A., Post, E., Reid, P.C., Stenseth, N.C., 2001 Ecological effects of the North Atlantic Oscillation. Oecologia 128, 1-14.

Ottersen, G., Hjermann, D.O., Stenseth, N.C., 2006. Changes in spawning stock structure strengthen the link between climate and recruitment in heavily fished cod (Gadus morhua) stocks. Fisheries Oceanography 15, 230-243.

Painting, S.J., Hutchings, L., Hugget, J.A., Korrübel, J.L., Richardson, A.J., Verheye, H.M., 1998. Environmental and biological monitoring for forecasting anchovy recruitment in the Southern Benguela upwelling region. Fisheries Oceanography 7 (3/4), 364-374.

Pedersen, O.P., Tande, K.S., Slagstad, D., 2001. A model study of demography and spatial distribution of Calanus finmarchicus at the Norwegian coast. Deep-Sea Research II 48, 567-587. 
Petereit, C., Haslob, H., Kraus, G., Clemmesen, C., 2008. The effect of temperature on the development of Baltic and North Sea sprat early life history. Marine Biology 154, 295-306.

Planque, B., Reid, P.C., 1998. Predicting the abundance of C. finmarchicus from a climate signal. Journal of Marine Biological Association of the United Kingdom 78, 1015-1018

Planque, B., Taylor, A.H., 1998. Long-term changes in plankton and the climate of the North Atlantic. ICES Journal Marine Science 78, 1015-1018.

Plante, S., Chabot, D., Dutil, J.D., 1998. Hypoxia tolerance in Atlantic cod. Journal of Fisheries Biology 53, 1342-1356.

Reid, P.C., Edwards, M.E., Hunt, H., Warner, A.E., 1998a. Phytoplankton change in the North Atlantic. Nature 391, 546.

Reid, P.C., Planque, B., Edwards, 1998b. Is observed variability in the long-term results of the Continuous Plankton Recorder survey a response to climate change? Fisheries Oceanography 7 (3/4), 282-288.

Robichaud, D., Rose, G.A., 2001. Multiyear homing of Atlantic cod to spawning ground. Canadian Journal of Fisheries and Aquatic Science 58, 2325-2329.

Rose, K.A., Christensen, S.W., DeAngelis, D.L., 1993. Individual-based modelling of populations with high mortality: a new method based on following a fixed number of model individuals. Ecological Modeling 68, 273-292.

Rose, K.A., Cowan Jr., Clark, M.E., Houde, M.E., Wang, S.B., 1999. An individual-based model of bay anchovy population dynamics in the mesoscale region of Chesapeake Bay. Marine Ecology Progress Series 185, 113-132.

Rothschild, B.J., 2000. Fish stock and recruitment: the past thirty years. ICES Journal of Marine Science 57, 191-201.

Rothschild, B.J., Osborn, T.R., 1988. Small-scale turbulence and plankton contact rates. Journal of Plankton Research 10, 465-474.

Schaber, M., Hinrichsen, H.-H., Neuenfeldt, S., Voss, R., 2008. Hydroacoustic tracking of Baltic cod (Gadus morhua L.)-Distribution in relation to hydrography in contrasting environments. Marine Ecology Progress Series, in press. Shaffer, G., 1979. Conservation calculations in natural coordinates (with an example from the Baltic). Journal of Physical Oceanography 9, 847-855.
Smith, N.P., Stoner, A., 1993. Computer simulation of larval transport through tidal channels: role of vertical migration. Estuarine and Coastal Shelf Science 37, 43-58.

Stephens, J.A., Jordan, M.B., Taylor, A.H., Proctor, R., 1998. The effects of fluctuations in North Sea flow on zooplankton abundance. Journal of Plankton Research 20, 943-956.

Turner, K., Righton, D., Metcalfe, J.D., 2002. The dispersal patterns and behaviour of North Sea cod (Gadus morhua L.) studied using electronic data storage tags. Hydrobiologia 483, 2001-2008.

Voss, R., Hinrichsen, H.-H., 2003. Sources of uncertainty in ichthyoplankton surveys: modeling the influence of wind forcing and survey strategy on abundance estimates. Journal of Marine Systems 43, 87-103.

Voss, R., Clemmesen, C., Baumann, H., Hinrichsen, H.-H., 2006. Baltic sprat larvae: coupling food availability, larval condition and survival. Marine Ecology Progress Series 308, 243-254.

Voss, R., Dickmann, M., Hinrichsen, H.-H., Floeter, J., 2008. Environmental factors influencing larval sprat Sprattus sprattus feeding in the Baltic Sea. Fisheries Oceanography 17 (3), 219-230.

Werner, F.E., Page, F.H., Lynch, D.R., Loder, J.W., Lough, R.G., Perry, R.I., Greenberg, D.A., Sinclair, M.M., 1993. Influences of mean advection and simple behaviour on the distribution of cod and haddock early life stages on Georges Bank. Fisheries Oceanography 2, 43-64.

Werner, F.E., Perry, R.I., Lough, R.G., Naimie, C.E., 1996. Trophodynamics and advective influences on Georges Bank larval cod and haddock. Deep-Sea Research II 43, 1793-1822.

Wieland, K., Jarre-Teichmann, A., Horbowa, K., 2000. Changes in the timing of spawning of Baltic cod: possible causes and implications for recruitment. ICES Journal of Marine Science 57, 452-464.

Zeldis, J.R., Oldman, J., Ballara, S.L., Richards, L.A., 2005. Physical fluxes, pelagic ecosystem structure, and larval fish survival in Hauraki Gulf, New Zealand. Canadian Journal of Fisheries and Aquatic Science 62, 593-610. 